Portland State University

PDXScholar

$1-1-2009$

\title{
Factors Associated with Inclusion of Spirituality in Secular Social Work Education
}

Leslie Grace Wuest

Portland State University

Follow this and additional works at: https://pdxscholar.library.pdx.edu/open_access_etds Let us know how access to this document benefits you.

\section{Recommended Citation}

Wuest, Leslie Grace, "Factors Associated with Inclusion of Spirituality in Secular Social Work Education" (2009). Dissertations and Theses. Paper 301.

https://doi.org/10.15760/etd.301

This Dissertation is brought to you for free and open access. It has been accepted for inclusion in Dissertations and Theses by an authorized administrator of PDXScholar. Please contact us if we can make this document more accessible: pdxscholar@pdx.edu. 
Factors Associated with Inclusion of Spirituality

in Secular Social Work Education

by

Leslie Grace Wuest

A dissertation submitted in partial fulfillment of the requirements for the degree of

Doctor of Philosophy

in

Social Work and Social Research

\section{Dissertation Committee: \\ Daniel Coleman, Chair \\ Pauline Jivanjee \\ Nancy Koroloff \\ Richard Hunter \\ Leslie McBride}

Portland State University

2009 


\begin{abstract}
In a diverse society, social work practitioners must be able to work with and respect people from a wide variety of cultures and ethnicities and with different value systems and ideological perspectives, including spiritual or religious beliefs.

Accordingly, social work education has begun to incorporate the topic of spirituality. This study builds upon previous studies by Dudley and Helfgott (1990) and Sheridan et al. (1994) which focused on views of faculty members regarding spirituality in social work education and support for a course on spirituality in the social work curriculum. This study goes on to examine inclusion of spirituality in general social work courses.
\end{abstract}

The study involved a survey of social work faculty members who teach courses in direct practice, human development, and diversity, with a response rate of $52 \%(N=222)$. The 40 -item web survey replicated items regarding faculty views about spirituality and social work, and measures of personal experience with spirituality from Sheridan's (1994) survey. Items regarding faculty and student inclusion of spirituality, classroom management strategies, and discussion outcomes were original to this study.

Results showed that in addition to 9 faculty who teach courses in spirituality, $75.1 \%$ of faculty members surveyed report a moderate or substantial discussion of spirituality in half of the courses they teach. Multiple regression analyses showed an association of faculty inclusion of spirituality to student inclusion and constructive 
discussions of spirituality, the school offering a separate course on spirituality, female gender, and full time status $(p<.001)$. Faculty-reported student inclusion of spirituality was associated with faculty inclusion, conflictual discussions, constructive discussions, and use of classroom rules $(p<.001)$. Constructive discussions of spirituality were associated with use of modeling and facilitation, faculty inclusion, and student inclusion of spirituality $(p<.001)$.

Several path models were compared using AMOS software. Results suggest that when faculty members include spirituality, students are more likely to discuss the topic. Faculty members report frequently including the topic of spirituality in the content of general social work courses. Classroom rules are related to increased student participation, and modeling and facilitation promote constructive discussion of spirituality. 


\section{Dedication}

to those who believe,

and to the One who gives them

joy beyond measure 


\section{Acknowledgments}

\section{Dissertation Chair}

\section{Dan Coleman}

Gave much of his time and attention to this project over several years, even from Vienna! He is the consummate researcher, and has taught me so much.

$\underline{\text { Dissertation Committee }}$

Pauline Jivanjee

Nancy Koroloff

Richard Hunter

Leslie McBride

Each spent long hours carefully reading a series of manuscripts, giving suggestions and making corrections. Our discussions were wonderful. The best committee ever!

\section{Survey Participants}

I am grateful to the 222 social work faculty members who took time out of their busy days to participate in this survey. Many added thoughtful comments about their experiences with spirituality in the classroom and in their lives.

Colleagues and Friends

To fellow students, particularly Mary Ann Dearborn and Jan Carpenter, who shared this journey with me and encouraged me along the way. To many friends both in Portland and Eugene who cheered me on again and again.

$\underline{\text { Family }}$

My mother has always been and continues to be my greatest supporter, period. My siblings and their families are a joy and a treasure. 


\section{Table of Contents}

Abstract

Dedication $\quad$ iii

Acknowledgments $\quad$ iv

Table of Contents $\quad \mathrm{V}$

List of Tables $\quad$ vi

List of Figures viii

Chapter 1: Introduction 1

Chapter 2: Review of the Literature 5

Chapter 3: Theoretical Framework 35

Chapter 4: Research Questions and Hypotheses 41

Chapter 5: Methods 44

Chapter 6: Results $\quad 59$

$\begin{array}{ll}\text { Chapter 7: Discussion } & 78\end{array}$

$\begin{array}{ll}\text { References } & 96\end{array}$

Appendices

$\begin{array}{lll}\text { Appendix A Transcripts of Participant Contacts } & 104\end{array}$

Appendix B Website Cover Letter 106

$\begin{array}{lll}\text { Appendix C Faculty Survey } & 107\end{array}$

$\begin{array}{lll}\text { Appendix D Human Subjects Application } & 115\end{array}$

Appendix E Correlation Table for Research Questions 4-6 119 


\section{List of Tables}

Table 1: $\quad$ Demographic Information 46

$\begin{array}{ll}\text { Table 2: } & \text { Ethnicity }\end{array}$

$\begin{array}{ll}\text { Table 3: } & \text { Spiritual Orientation }\end{array}$

Table 4: $\quad$ Spiritual Identification: Social Work Faculty compared with $\quad 48$ United States General Population

Table 5: $\quad$ Item Correlations: Faculty Inclusion of Spirituality 51

Table 6: $\quad$ Item Correlations: Student Inclusion of Spirituality 51

Table 7: $\quad$ Correlations of faculty preparedness variables $\quad 54$

Table 8: $\quad$ Frequency of Attendance at Religious Services 56

Table 9: $\quad$ Current Spiritual Practices and Current Participation 57 and Involvement

Table 10: $\quad$ Personal Experience Correlations 58

Table 11: $\quad$ Comparison of Vote for Separate Course in Spirituality 59 Across Three Studies

Table 12: $\quad$ Logistic Regression Predicting Support for Required Course $\quad 63$ in Spirituality

Table 13: $\quad$ Standard Multiple Regression Predicting Faculty Views of

Table 14: $\quad$ Degree to which spirituality is included in social work courses $\quad 65$

Table 15: $\quad$ Standard Multiple Regression Predicting Faculty Inclusion $\quad 67$ of Spirituality

Table 16: $\quad$ Standard Multiple Regression Predicting Student Inclusion $\quad 69$ of Spirituality

Table 17: $\quad$ Standard Multiple Regression Predicting Constructive Classroom Discussion of Spirituality 
Table 18: $\quad$ Standard Multiple Regression Predicting Faculty Inclusion for Faculty with Less Personal Experience with Spirituality

Table 19: $\quad$ Path Model Comparisons: Goodness of Fit Measures 


\section{List of Figures}

$\begin{array}{lll}\text { Figure 1: } & \text { Path Model A } & 73\end{array}$

$\begin{array}{lll}\text { Figure 2: } & \text { Path Model B } & 74\end{array}$

$\begin{array}{lll}\text { Figure 3: } & \text { Path Model C } & 74\end{array}$

Figure 4: $\quad$ Final path model with standardized coefficients and 77 Explained variance for outcome variables 


\section{Introduction}

Social work practice involves interaction with a wide variety of different racial and cultural groups currently represented in American society. In order to work within this multicultural environment, social workers must be able to respect and value people with a wide range of personal characteristics, values, and lifestyles. Accordingly, the Council on Social Work Education's Educational Policy and Accreditation Standards (Council on Social Work Education, 2001) state that one of the purposes of social work education is "preparing social workers to practice without discrimination, with respect, and with knowledge and skills related to clients' age, class, color, culture, disability, ethnicity, family structure, gender, marital status, national origin, race, religion, sex, and sexual orientation."

Schools of social work have adjusted curriculums to include teaching respect for aspects of diversity such as race, ethnicity, national origin, gender and sexual orientation, all of which are regularly included as topics of classroom discussion in courses across curriculum content areas. Other aspects of diversity may be mentioned but get much less attention, such as age, disability and religion. The focus of this study is spirituality, the broader context for religious belief. As will be discussed in more detail, spirituality is a prominent aspect of religious experience, but is also experienced apart from religion. This study therefore focuses on the more inclusive concept of spirituality.

As social workers relate to individuals, groups, families, and communities with widely divergent value systems and ideological perspectives, knowledge of and 
appreciation for various spiritual perspectives is critical. In order to form productive relationships and interact in meaningful ways with clients, social workers must be able to understand the perspective through which the client interprets the world (Dalton, 2005). This is particularly important because beliefs of social workers often differ from those of members of the larger population. While both have deeply held beliefs, social workers are far more likely to believe that truth is relative and socially constructed, while the general population is more likely to believe that truth is universal and transcendent (Canda \& Furman, 1999; Hodge, 2002b). Given the likelihood of different perspectives and value systems, social workers must be able to develop respect for people whose values and lifestyle choices differ from their own. For this reason, it is vital that social work education include content regarding spirituality in order to prepare social workers to provide quality services to clients with different ideological perspectives (Ai, 2002; Canda \& Furman, 1999; Cnaan, Wineburg, \& Boddie, 1999; Ellor, Netting, \& Thibault, 1999; Hodge, 2003a; Joseph, 1987; Sheridan, Wilmer, \& Atcheson, 1994).

In order to include spirituality in social work education, however, educators must agree that the topic is relevant to social work, be prepared to teach it, and have textbooks and professional articles that support classroom instruction. Spirituality and religion are experienced on a deeply personal level, evoking strong emotions, requiring a classroom environment of respect for diverse ideological perspectives. Due to the sensitive nature of the topic, and potential for conflict or heated discussion among students, educators may be cautious about including spirituality in social work courses. 
Survey research suggests that most social work educators view spirituality and religion as relevant to social work practice and social work education (Dudley \& Helfgott, 1990; Sheridan et al., 1994). Current research, however, reveals a lack of attention to the topics of spirituality and religion in leading social work literature and textbooks (Cnaan et al., 1999) and social workers are generally dissatisfied with the lack of coverage of spirituality and religion in their own graduate social work education (Ai, 2002; Ai, Moultine, Picciano, Nagda, \& Thurman, 2004; Cnaan et al., 1999; Sheridan, Bullis, Adcock, Berlin, \& Miller, 1992; Sheridan \& Hemert, 1999). In sum, although there is general consensus among social work practitioners and educators that spirituality is relevant to social work education, there is also consensus that social work education in the recent past has not adequately equipped social work students to understand or address issues of spirituality.

Schools of social work have recently begun to address this problem by incorporating separate elective courses in spirituality and religion into curriculums. There has also been an increase in overall research on spirituality in social work, and a corresponding increase in the number of articles in social work journals that address spirituality. So far, researchers have not specifically investigated the extent to which spirituality is included in general social work courses in the curriculum. In light of this recent increase in attention to spirituality, it is reasonable to expect that social work educators may currently be including the topic of spirituality more frequently in social work courses across curriculum content areas. This study examined this possibility, adding to existing knowledge by exploring: 1) the extent to which spirituality is currently included in faculty lectures, textbooks, and assigned readings; 
2) factors which predict inclusion of spirituality as a topic; and 3) factors predicting constructive classroom discussion about spirituality.

In the pages that follow, the context of the study is presented through a review of existing literature regarding relevance of spirituality to the social work profession, to clients, to graduate education overall, and specifically to social work education. Critical theory is then examined as a leading theoretical framework which, when applied to social work education, fosters respect for different ideological perspectives within the classroom. This discussion will be followed by a more in-depth statement of the research questions and methodology, results, and conclusion sections. 


\section{Review of the Literature}

\section{Spirituality and Social Work History}

Social work history has spiritual and religious roots. The initial forms of social work services consisted of voluntary charitable efforts of people largely motivated by spiritual convictions and values (Cnaan et al., 1999; Ellor et al., 1999; Niebhur, 1932). The earliest form of welfare to the poor and disadvantaged in American society was provision of charity by members of the local community, primarily organized by religious leaders in local congregations. During the early1800s, new opportunities for employment and increased immigration from other countries resulted in a large population increase in urban areas. One consequence of this growth was greater numbers of unemployed, disabled, and otherwise destitute people in the cities, exceeding the capacity of existing charity provision. Local governments responded by developing forms of institutional care such as poorhouses or almshouses for the poor, orphaned and disabled (Ellor et al., 1999).

Private charity organizations run by Protestant, Catholic, and Jewish groups, or "benevolent societies," also responded to the crisis by organizing voluntary associations with names that described their purpose. Examples are: The Society for Poor Widows with Small Children, Home for Little Wanderers, The Ladies Benevolent Society, the Female Charitable Societies, and the Hebrew Benevolent and Orphan Asylum Society (Ellor et al., 1999; Olasky, 1992). These associations engaged in the provision of monetary assistance and spiritual encouragement by 
mostly female volunteers, emphasizing personal, supportive contact between giver and receiver (Keith-Lucas, 1989; Olasky, 1992). Ellor, Netting and Thibault (1999) note that the rapid increase in private benevolent societies coincides with the timing of the Second Great Awakening which took place in the early 1800s; a religious revival which inspired large numbers of citizens to reach out to their neighbors in charitable activity. The prevailing view at the time was that poverty was primarily the result of poor choices, and that moral education and "spiritual uplift" would be the greatest way to help lift people out of poverty.

During the late 1800 s, concern developed over the lack of coordination between the multitude of private and public charities operating in largely urban areas (Ellor et al., 1999). This resulted in the introduction of the Charity Organization Society (COS) in 1877 in Buffalo, New York, by Episcopal priest, S. Humphreys Gurteen, based on the London Society for Organizing Charitable Relief and Repressing Mendicancy (DuBois \& Miley, 2005). The founder of the original Settlement House, London's Toynbee Hall, was also a clergy member, Anglican priest Samuel Barnett. Several authors note that many of the reformers of the time had spiritual roots. Spencer (1957) states that

The reform period, starting in the latter part of the nineteenth century and carrying over into the first decade or so of the present century, was studded with dynamic personalities, many of them spurred on by religious fervor, who started reforms in asylums, prisons, sweatshops, and slums (p. 521). 
Similarly, Marty (1980) states that "Most of what historians know about agencies of concern, charity, and welfare until about a century ago connects them with some sort of religious impulse or auspice (p. 463).”

Many of these social work pioneers cared about the poor and oppressed in their communities out of the conviction that all people are created by a transcendent God and therefore have inherent dignity and worth, and that God calls the faithful to a life of service to others. In an ultimate sense, the poor were seen as their "brothers and sisters." They gave and served out of gratitude for what they had received, both in material goods and spiritual blessings. Other early social workers were motivated primarily by Enlightenment and Humanistic principles, which also affirmed the worth and dignity of the individual and encouraged giving to others. Alan Keith-Lucas (1989) views a blending of evangelical and humanitarian philosophies as providing the primary underlying motivations behind development of the early Settlement House Movement. Martin Marty also notes that Jane Addams "fused Quakerism with Darwinism, pragmatism, 'experience,' and value theory (Marty, 1980, p. 476).”

During the late 1800s secular humanistic philosophy had replaced religion or theism as the predominant worldview for many Americans, influenced by the Age of Enlightenment. Charles Darwin published the Origin of the Species in 1859, explaining the existence and complexity of life primarily by naturalistic explanations, rather than religious ones (Johnson, 1993). The Enlightenment contributed the assertion that values and morals, previously understood to be absolute and universal, were rather to be understood as personal, depending on individual perspectives and experience. Science now took the place of God as the recognized source of authority 
and knowledge. A medical model was adopted in health care, and professions gained respect and stature through their use of the scientific method for generating knowledge.

The Progressive Era of the early 1900s continued this trend toward secularization of charity work and the development of social work as a profession. Spencer (1957) notes that the ten year period between 1920 and 1930 ...was marked throughout the world by a loss of confidence in, or a turning away from, religion; by a cynicism and marked sense of irresponsibility for one's fellows; and by an increase in agnostic and atheistic attitudes, particularly among college-age youth. (p. 521)

Two other prominent theoretical systems contributing to this shift away from religion were introduced into this country in the years leading up to the 1920s. Sigmund Freud provided scientific explanations for psychological processes; and Karl Marx promoted scientific socialism, an economic understanding of power relations in society. Both systems replaced faith in a transcendent God with rational, scientific explanations for human behavior, motivation, and social processes.

With increasing acceptance of science and secular humanism as the basis for the major professions, and criticism in 1915 from Abraham Flexner that social work was not yet a true profession, social work was motivated to adopt a more scientific and pragmatic approach, purposely distancing itself from religion and spirituality (Cnaan et al., 1999). As a result, the provision of charity progressed toward a more structured, scientific process carried out by trained professionals, ultimately leading to the predominantly secular profession of today. 
While scientific ways of knowing continue to be highly valued within social work, the profession has also incorporated the postmodern perspective. Following in the wake of the Enlightenment, postmodern thought posits that reality is subjectively known and that truth is individually and socially constructed, informed by personal experience. While largely a secular perspective, the concept of reality as a social construction incorporates consideration of the role that beliefs and values play in determining an individual's perception of reality; including spiritual beliefs and values. In addition, organizations such as the Society for Spirituality and Social Work and the North American Association of Christians in Social Work, along with the Journal of Religion and Spirituality in Social Work have advocated for increased sensitivity to the role that spiritual or religious beliefs play in the lives of clients. As a result, spirituality and religion are increasingly recognized as relevant to social work practice and social work education.

Spirituality and Social Work Values

The profession of social work is grounded in a value system which emphasizes the worth and dignity of all people and the related values of self-determination, honoring cultural diversity, strengths-based practice, and the importance of social support networks. These values will now be examined in relation to spirituality. Respect for the client as an individual of worth and dignity includes respect for their innate wisdom, ability, and right to make decisions about their own goals and lifestyle based on personal values and priorities. These values and priorities stem from the individual's underlying worldview, grounded in cultural understandings of life which often involve some form of spiritual and religious beliefs. This concept of self- 
determination therefore includes awareness of and respect for personal beliefs and spirituality.

The profession of social work honors the richness of cultural diversity in our society. As noted above, in addition to membership in a particular racial group, individuals are members of a cultural or ethnic group which shares a common language, dress, foods, and behavioral expectations. A deeper understanding of culture, however, includes recognition of a shared belief system that defines that which is important, good, and true in a philosophical and religious sense (Hunter, 1991). A culture's shared understandings may include beliefs about the meaning and purpose of life, the origin of the universe, and what happens after death. The unique lens through which a particular culture views the world must be understood in order to communicate meaningfully with people from that culture (Hodge, 2003b). A culture's belief system is reinforced and perpetuated through spiritual practices and participation in religious activities. While social work educators are increasingly aware of the relevance of culture to social work practice, there has been less attention to the role of spirituality in cultural experience.

Social work also emphasizes strengths-based practice, recognizing that individuals have abilities and competencies to draw on when dealing with challenges. "Strengths-based approaches focus on client strengths, on the strengths in the helping relationship or in the context in which helping takes place, and on strengths or resources in the environment which people can use to achieve greater equality" (Gibbons \& Gray, 2004, p. 26). Clinicians using a strengths-based approach do not see themselves as "the experts," but view clients as experts regarding the dynamics of 
their particular situation; helping clients utilize their own wisdom and experience. In using a strengths-based approach, social workers "focus ... on the meaning that clients attach to their experience, the way in which people construct meaning for themselves" (Gibbons \& Gray, 2004, p. 26). A person's spirituality and belief system offers a way to make sense of events in life, including ways to cope with problems or crises. For social workers to fully appreciate and build upon clients' strengths and cultural values, they must have some understanding of the role that spirituality plays in many people's lives.

In recognizing a person's strengths, clinicians also look at strengths in a person's social support networks, including involvement in social groups or organizations in the community. "Informal social networks are a significant source of support for mediating stress and increasing one's competence and sense of control" (DuBois \& Miley, 2005, p. 24). Spiritual and religious organizations play a vital role as social support networks, both for individuals and communities. Spiritual congregations exist in every community, urban and rural, ministering not only to spiritual, but also physical and social needs of those who attend as well as members of the surrounding community. The National Association of Social Workers (NASW) acknowledges the valuable role that religious organizations have played in providing social services and material assistance to the poor. They also note that social workers are actively engaged with religious organizations as administrators, employees, and evaluators. "Data from NASWs' Practice Research Network...indicates that 12 percent of the association's members work in sectarian settings" (NASW, 2002a, p. 10). Jewish Family and Child Service, Catholic Charities, and Lutheran Family 
Service have all provided professional, secular social services for many years through federal, state, and county contracts (Haught, 2001).

In ministering to physical and social needs of the larger community, congregations provide services that range from soup kitchens, clothing and food distribution to programs for the homeless, elderly, at-risk youth, families in transition from welfare to work, and prisoners and their families as well as professional services for those in need of intensive counseling or rehabilitation with mental health or substance use issues.

Spiritual and religious congregations promote values that foster stability and well-being, providing an environment conducive to the formation of nurturing relationships, physical protection, safety, structure and stability (Brazelton \& Greenspan, 2000). Many congregations provide an opportunity to interact and form relationships with people from diverse ethnic and socioeconomic groups, sharing a common bond of beliefs and values. Long-term relationships within congregations provide an ongoing support system for families and children, creating a "center of stability for families that endures despite upheavals that might occur at home" (Brazelton \& Greenspan, 2000, p 167). In times of crisis people often turn to their faith and to spiritual or religious communities for support and comfort, particularly when facing serious or terminal illness and the loss of a loved one (Miller, 2001). Religious organizations in the community are resources for clinicians supporting individual client strengths as well as community-based social workers who form alliances with clergy in creating community support networks. 
While acknowledging positive aspects of social support networks, it is also important to acknowledge potential difficulties associated with spiritual or religious activities and belief systems. Deeply held beliefs can unify a group of people, and at the same time distance participants from their community. Even within a particular religious denomination, beliefs vary widely, ranging from very conservative or orthodox to very liberal or progressive (Hunter, 1991), leading to conflict both within denominations and with members of the larger community over controversial issues such as homosexuality and abortion rights. Social workers need to be sensitive to the possibility that clients may have had negative experiences with spirituality or religion, creating hurt or resentment that may be relevant to mental health and treatment issues.

In light of the profession's emphasis on valuing client self-determination, strengths-based practice, the relevance of clients' social support network and respect for the richness of cultural diversity represented in our society, social work students need to understand the role spirituality plays in each of these areas and be equipped to address issues involving spirituality in social work practice.

\section{Spirituality, Health and Mental Health}

For purposes of this discussion, the concepts of spirituality and religion as defined by Sheridan will be used here:

Spirituality is defined as 'the human search for meaning, purpose and connection with self, others, the universe, and ultimate reality, however one understands it. This may or may not be expressed through religious forms or institutions.' Religion is defined as 'an organized and structured set of beliefs 
and practices shared by a community that is related to spirituality.' (Sheridan et al., 1994, p 363)

The larger concept of spirituality is the primary topic of interest here; the overall search for meaning and purpose, and connection with a transcendent reality (Ai, 2002; Bullis, 1996; Canda \& Furman, 1999). Bullis defines spirituality as "the inner feelings and experiences of the immediacy of a higher power....the relationship of the human person to something or someone who transcends themselves" (Bullis, 1996, p.2). Religion can be understood in this context as a particular manifestation of spirituality. As noted in the definition, spirituality does not necessarily include forms of organized religion; however religion normally does involve spirituality. References to spirituality in this paper are intended to indicate the larger concept including both organized religion and more general expressions of spirituality.

What makes these topics particularly relevant for social work education today is the resurgence of interest in spirituality and religion among the general public. According to the Gallup Poll, religion plays an important part in the lives of $85 \%$ of the American people. "More than 6 in 10 Americans say that religion is very important to them in their own lives, and another $24 \%$ say that religion is fairly important in their lives. That leaves $15 \%$ who say that religion is not very important" (Newport, 2004, p. 111). Baylor University researchers found that 63\% of people not affiliated with religion still believe in God or a higher power, and that almost a third of this group sometimes pray (Baylor University, 2006). This reflects the growing number of Americans who are spiritual, but whose beliefs do not fall within the confines of traditional Judeo-Christian religion. 
In the past century, popular interest in spirituality has manifested itself in many forms, including mysticism, Eastern religions, New Age consciousness, Goddess worship, spiritual psychics, and Neo-Native American spirituality (Ai, 2002; Bullis, 1996; Canda \& Furman, 1999; Roof, 1993). New Thought, a spiritual movement which developed in America in the 19th Century, represents a loose connection of spiritual and religious groups that share a belief that God or the divine is in all things and the mind is capable of healing the body (ReligionFacts, 2007). New Thought is reflected in churches such as the Unity Church and Religious Science, and organizations such as the Living Enrichment Center and the International Metaphysical League. The importance of this spiritual movement is reflected in the popularity of current best-selling authors and speakers Deepak Chopra, Wayne Dyer, and Rhonda Bryne.

Broadly defined as the human search for meaning, purpose and connection with self, others, the universe, and ultimate reality, spirituality can be understood as part of normal human experience. As noted earlier, one aspect of culture involves a shared set of beliefs that attempt to explain these grand mysteries of human life. Wringe (2002) describes spirituality as the process of coming to understand our place in the physical and social world in which we live.

A growing awareness of the universe and its magnitude, of the natural world and its antiquity, intricacy, beauty and fragility, of other people, their achievements, strivings and sufferings is scarcely separable from a view of oneself in relation to them. (p. 163) 
In the Social Work Dictionary, Barker (2003) identifies four basic human needs, including aspects of spirituality which are often met in the context of spiritual communities:

Human needs include physical aspects (food, shelter, safety, health care, and protection), personal fulfillment (education, recreation, values, aesthetics, religion, and accomplishment), emotional needs (a sense of belonging, mutual caring, and companionship), and an adequate self-concept (self-confidence, self-esteem, and identity). (Barker, 2003, p. 403)

Influential thinkers Gordon Allport, Erick Fromm, and Abraham Maslow all recognized an underlying "core of spiritual needs and values" vital to human experience (Wulff, 1996, p. 60). Psychologists William James and Erik Erikson also viewed religion as meeting human needs and making unique contributions to human development across the lifespan (Wulff, 1996). Spirituality and religion are widely recognized as aspects of human experience that play an important role in many peoples' lives.

The literature regarding the relationship between spirituality, health, and mental health focuses to a great extent on religion rather than the larger, more abstract construct of spirituality. Many researchers use the more concrete variables of attendance and well-established measures of religious practices rather than exploring less tangible constructs associated with spirituality. This review of the literature reflects the emphasis of current empirical research on religion. As research regarding this topic matures, researchers are increasingly developing and including measures of spirituality. 
Gordon Allport (1950) identified two levels of religiosity: intrinsic and extrinsic. Extrinsic religiosity refers to church attendance for primarily social reasons; to belong, find friends, or fulfill role demands. Intrinsic religiosity refers to attendance for primarily spiritual reasons; to draw closer to God, affecting everyday decisions and lifestyle. Early research on religion combines both concepts into a general measure of religiosity; more recent research tends to include separate measures of church attendance and internal spiritual commitment.

In a review of research on religion and health, Koenig (1999) found strong evidence that frequency of attendance at religious services and practice of private devotion are positively related to levels of general satisfaction in life and overall quality of life. Research on marital satisfaction indicated that married couples who share a common belief system, indicated by attending religious services together, have high levels of marital satisfaction, and are less likely to divorce (Koenig, 1999).

Research shows a correlation between religious attendance and belief and healthy lifestyles. People who regularly attend services or engage in private spiritual practices are less likely to smoke cigarettes, and when they do smoke, smoke fewer cigarettes a day (Koenig, 1999). Studies find significantly lower rates of alcohol and drug use and dependence for those who attended religious services regularly (Gartner, 1996; Koenig, 1999). Literature on adolescent substance use shows that adolescents who attend religious services have reduced risk of becoming regular users of substances, and those who do experiment with drugs or alcohol are less likely to develop a habit (Koenig, 1999). Incidence of delinquency is also reduced for those who participate in religious services (Gartner, 1996). 
Health researchers have studied differences in physiological functioning between people who attend religious services and those who do not. Cholesterol levels, including triglycerides and LDL were lower in youth from religious families (Koenig, 1999); and blood pressure was lower in men with high church attendance (Gartner, 1996; Koenig, 1999). In an extensive review of the literature Gartner (1996) noted a correlation between religious participation and longevity, and a corresponding lower risk of deaths from coronary heart disease (Gartner, 1996).

Longitudinal studies of mortality among the elderly poor found that during the duration of the study, impoverished older people who were religious were less likely to die than the nonreligious (Koenig, 1999). Frequency of attendance at religious services correlates with reduced levels of functional disability as people age. Those who attend church more frequently are able to live independently longer with fewer complications from general disability, stroke related paralysis, diabetes, broken bones, amputations, heart disease and mental deterioration (Koenig, 1999). Health researchers are increasingly including religion as a potential protective factor along with other health variables such as diet and exercise.

Research has also shown that spiritual beliefs and involvement in a spiritual community contribute to improved mental health. Galanter and Buckley (1978) studied the connection between mental health and measures of spirituality that included both evangelical religion and spiritual meditation, finding a correlation between meaningful spiritual experiences and "significant reduction in symptoms of anxiety, depression, suicidal thoughts, and substance abuse." These positive mental health outcomes may be attributed to improved ability to deal with stress. Pargament 
and colleagues (1990) studied both religious and nonreligious coping techniques used by people who faced significant negative life events such as illness, injury, death, separation or divorce or loss of employment. They found that people who rely on religious faith to help them cope with these major life stressors have better emotional outcomes than those who use nonreligious techniques.

Other research confirms a relationship between religious coping skills and lower levels of suicidal ideation, suicide rates, and depression (Gartner, 1996; Koenig, 1999). Gartner (1996) found some studies that claim an association between religiosity and negative mental health condition such as authoritarianism, rigidity, dependence and self-actualization, but noted that measures used in these studies largely pathologized religious belief, and therefore have questionable validity. According to Gartner's (1996) review, the literature regarding the relationship between religious beliefs and anxiety, psychosis, and self-esteem resulted in mixed findings and inconclusive evidence.

Ellison and Levin (1998) reviewed medical studies on the relationship between religion and health, noting that the quality of research in this area has improved with time, including designs which control for variables such as age, gender, ethnicity, education, socioeconomic status, health conditions, stressors, and religious affiliation. In their review of the literature, Oman and Thoresen (2002) identified four mechanisms that have been used to explain the connection between religion and spirituality with positive health outcomes including (1) promoting development and maintenance of positive health behaviors; (2) social support, affecting physical and emotional health, and disease detection and treatment; (3) "enhanced psychological 
states (faith, hope, and inner peace)," promoting healthy immune and endocrine systems as well as affecting positive health behaviors; and (4) direct effects of prayer and spiritual healing on physical symptoms through "superemperical pathways" operating beyond the boundary of current scientific understanding (Oman \& Thoresen, 2002, p. 371).

In sum, spiritual beliefs and religious affiliation play a role in promoting healthy lifestyles and reducing stress, and may contribute to improved physical and mental health through a number of different pathways.

\section{Spirituality and Education}

The nursing profession was among the first to recognize the importance of spirituality in the lives of patients, perhaps due to the nature of their work with patients dealing with major life crises. The nursing profession advocated for the inclusion of chaplains on medical teams during the 1980s, and added the spiritual dimension to the prevalent mind/body paradigm used in nursing education (Koenig, 1999). Following the lead of the nursing profession, the medical profession has increasingly recognized the role of spirituality in patient care and recovery. The Accreditation Council for Graduate Medical Education (ACGME) recently incorporated material on spirituality in medical residency programs because "clinical evidence is increasingly clear that physicians who cannot connect with the 'heart and soul' of the patient are less likely to be healers than those who can" (Palmer, 2003, p. 380).

Complementary and alternative medicine (CAM), which emphasizes nonmedically based holistic forms of treatment, is becoming increasingly accepted as an 
optional way of treating patients. One aspect of CAM is mind-body medicine, which strives to improve or heal bodily function by engaging the mind. Mind-body methods include spiritual exercises such as mindfulness meditation, prayer, affirmations, Hatha yoga, and Tai Chi Chuan (Mayo Clinic, 2007; NIH, 2005).

British educators have recognized the importance of including spirituality in education, with passage in 1988 of the Education Reform Act, which "requires that the school curriculum should promote the spiritual development of both pupils in school and of society, alongside their moral, cultural, mental and physical development" (Wringe, 2002, p. 157). American educators have also recently embraced the inclusion of spirituality in education. Parker Palmer, a leader in the field of education in the United States, has developed a widely-used teacher education program based on his book Courage to Teach: Exploring the Inner Landscape of a Teacher's Life (Palmer, 1998). The program, involving eight three-day retreats which take place over a two year period, helps K-12 teachers avoid burnout and increase receptivity to the needs of students through spiritual practices such as "solitude and silence, meditative reading, walking in the woods, keeping a journal, and finding a friend who will listen" (Sparks, 2003, p. 50).

Literature regarding diversity education was also reviewed, particularly in relation to facilitation of classroom discussion involving sensitive topics. Garmon (2005), noting that individuals approach diversity issues in unique ways depending on personality, attitudinal, belief and experience factors, identifies two sets of variables associated with positive response to multicultural teacher education: 1) personal disposition variables (are open, self-aware/self-reflective, and committed to social 
justice) and 2) experience variables (have had intercultural, educational, and support group experiences regarding diversity) (Garmon, 2005). The current proposal incorporates Garmons' experience variables as factors which contribute to faculty outcomes and therefore will be further defined.

Intercultural experience. Positive personal contact with acquaintances or friends who are members of diverse groups or experience of belonging to a minority group leads to positive perceptions and responses to diversity. Garmon (2005) notes that negative cross-cultural experiences have the opposite effect, creating negative perceptions and responses.

Educational experience. On-going multicultural education is necessary to help individuals integrate information on diversity issues over time and across subject areas (Garmon, 2005; Petrovich \& Lowe, 2005).

Support group experiences. Support involves the creation of a safe environment where individuals can explore their own attitudes as well as the views and experiences of others (Garmon, 2005).

Garmon's model hypothesizing factors contributing to an individual's response to multicultural diversity suggests that receptivity to diversity issues may be positively impacted through positive contact with members of minority groups and open discussion of differing perspectives, as well as traditional diversity education. David Hodge (2003) also suggests that positive personal experience with people who value spirituality will lead to more awareness, understanding and openness to people of faith. He contends that faculty members and students of schools of social work may 
not have personal friends or acquaintances who value spirituality, and therefore do not have a frame of reference for understanding or relating to spirituality or religion.

In a qualitative study by Petrovich and Lowe (2005), social work graduate students and alumni emphasized the need for a safe and supportive classroom environment when discussing potentially anxiety-provoking topics. Factors associated with classroom safety were class size and attitudes and behavior of faculty members. The behavior of faculty members most valued by students was modeling respect for diverse ideas and experiences; accepting and encouraging student viewpoints (Petrovich \& Lowe, 2005). Albert Bandura originally developed the concept of modeling as a teaching strategy for either encouraging or inhibiting specific student behaviors (Knowles, 1978). Modeling respect for diversity is one of three strategies identified in the literature for creating safety within the classroom environment.

A second method of creating safety and support for diverse views is the use of classroom rules. Rendon (2000) developed a model of teaching which fosters a sense of community within diversity in higher education. An important aspect of her model is the establishment of classroom rules that create a climate where different ideas and ways of knowing are honored and respected. Palmer (1990) uses rules to set parameters for discussion which also sets an expectation for transparency and honest sharing. In a sense, rules comprise a contract between students and the professor; if students will allow themselves to be vulnerable in classroom discussion, the professor will intervene and moderate conflict if someone attacks their ideas or point of view.

A third method of creating a safe classroom environment, in addition to the use of modeling and rules, is facilitation of classroom discussion in a way that both 
encourages open dialogue and intervenes to move discussion in positive directions if there is conflict. Saleeby and Scanlon (2005) advocate the use of "the insights and methods of group process and group work to help students engage, to balance power inequities in classroom conversations, and to assist in recasting and reconfiguring differences of opinion as a way of embracing ambiguity" (Saleebey \& Scanlon, 2005, p 12). All three classroom management strategies: modeling, use of rules, and group facilitation will also be addressed later in the context of the theoretical framework of Critical Pedagogy.

Spirituality and Social Work Education

As noted previously, the Educational Policy and Accreditation Standards of the Council on Social Work Education (Council on Social Work Education, 2001) includes religion as one of a number of client characteristics that social work education needs to address in order to "[prepare] social workers to practice without discrimination, with respect, and with knowledge and skills." Graduates from schools of social work are to demonstrate the ability to work with clients representing a vast spectrum of diversity, including diverse spiritual or religious perspectives. The Accreditation Standards then discuss key curriculum content, which addresses specific topic areas covered in social work education. In the area of Human Behavior and the Social Environment, coursework content "includes theories and knowledge of biological, sociological, cultural, psychological, and spiritual development across the life span; the range of social systems in which people live...; and the ways social systems promote or deter people in maintaining or achieving health and well-being" (Council on Social Work Education, 2001, p. 9). 
There is concern, however, that social work education for the most part does not include the topics of spirituality or religion. Martin Marty (1980) noted that “...most of the time the literature of the profession genially and serenely ignores religion" (p. 465). Cnaan, Boddie, and Wineburg (1999) performed an extensive review of textbook content, social work course outlines, abstracts of papers presented at the Annual Program Meetings (APM) of the Council on Social Work Education, articles abstracted in the Social Work Abstracts, as well as the National Association of Social Work Yearbooks and the Encyclopedia of Social Work. They found little mention of spirituality, and even less attention to the role of religion in social work. In their review of 20 popular social work textbooks, few entries referring to religion or spirituality were found, most of which were historical references concerning the Charity Organization Societies and the period up to the Great Depression and the Social Security Act of 1935. Only three textbooks, published between 1996 and 1998, included discussions of spirituality and religion.

When spirituality and religion are included in social work textbooks, they are many times described simplistically, according to common stereotypes. Hodge discusses the problem of negative portrayal of religious groups and individuals; “...by framing theists in a disparaging manner, they actively work against the development of an open, inclusive milieu that fosters respect for different worldviews" (Hodge, 2003a, p. 353).

In an extensive review of course outlines from faculty members from schools of social work across the United States who attended the 1993 and 1994 APM of the Council on Social Work Education, Cnaan and colleagues (1999) found little reference 
to spirituality or religion. "Our review of course outlines indicated that religious issues are generally ignored in secular schools" (Cnaan et al, 1999, p. 54). This was true for courses in policy, history of the profession, and human behavior and the social environment. David Hodge (2002a) reviewed four leading social work journals going back 10 years, looking for specific references to Evangelical religion, and found none.

Research also indicates dissatisfaction with the lack of content regarding spirituality in social work education among social work practitioners (Sheridan et al., 1992), students (Ai et al., 2004; Sheridan \& Hemert, 1999) and faculty members (Dudley \& Helfgott, 1990; Sheridan et al., 1994). Summing up the results of nine studies published in social work journals during the past decade, Ai (2004) found that "most respondents reported a positive attitude toward the role of religion and spirituality in practice. Up to $80 \%$ of respondents reported inadequate training in their graduate programs" (Ai et al., 2004, p. 109).

Two previous studies have been conducted exploring social work faculty views of religion and spirituality. James Dudley and Chava Helfgott's (1990) study included faculty members from four schools of social work on the East Coast, two public and two nonsectarian private universities. Out of 53 respondents, $75 \%$ agreed or strongly agreed that spirituality is a fundamental aspect of being human, while $13 \%$ disagreed or strongly disagreed and $11 \%$ had no opinion. Forty-seven percent agreed that social workers should become more sophisticated in spiritual matters. When asked if they would be in favor of a course in spirituality offered at their school which focused on the relationship between spirituality and social work, $28 \%$ said they would oppose the course, and $60 \%$ would support it only as an elective; less than $8 \%$ would support it as 
a required course. When asked if social workers should become more sophisticated in spiritual matters, $47 \%$ strongly agreed or agreed, $26 \%$ had no opinion, and $26 \%$ disagreed or strongly disagreed.

Michael Sheridan and colleagues' 1994 study included faculty members from 25 schools of social work in 12 Southeastern states and Washington D.C., representing public and private non-sectarian and sectarian universities. Out of 280 respondents, $90 \%$ agreed or strongly agreed that religious and spiritual beliefs are part of multicultural diversity, and $61.3 \%$ agreed or strongly agreed that spirituality is another dimension of human existence beyond the biopsychosocial framework currently used to understand human behavior. When asked if they would be in favor of a course in spirituality offered at their school which focused on the relationship between spirituality and social work, $16.1 \%$ said they would oppose the course, $62.4 \%$ would support it only as an elective, $6.2 \%$ would support it as a requirement in the clinical track only, $13.8 \%$ would support it as a required course for all students. Four faculty members said that they would rather see such content infused into existing courses. Most faculty reported that they received very little graduate training regarding spiritual and religious issues: $59 \%$ indicated that topics were never included, $29.7 \%$ rarely included, $8.6 \%$ sometimes included, and $2.7 \%$ often included. Sheridan et al. conclude that:

Given the apparent disparity between the importance of religion and spirituality in respondents' lives and the current lack of training on the subject in schools of social work, it is incumbent upon social work educators to struggle with the hard questions of content focus and teaching approaches in 
order to adequately prepare students for social work practice. (Sheridan et al., 1994, p. 375)

Sheridan et al. (1994) found that a positive view of the role of religion and spirituality in social work practice was the strongest predictor of support for a required course. She recommends further study of relationships between faculty views of the relevance of spirituality and religion to social work practice, support for a separate course on spirituality, and personal ideology.

Kilpatrick \& Puchalski (1999) surveyed deans of 56 schools of social work regarding curriculum inclusion of spirituality or religion; $75 \%$ reported that courses in the general curriculum included content on spirituality or religion, $44.6 \%$ of the deans reported that they offered a separate course on spirituality or religion in social work. Courses most likely to include spirituality or religion related to end of life care $(75 \%$ of schools), the role of spirituality in counseling clients (77\%), spirituality and social health (52\%), spirituality and mental health (50\%), and spirituality and physical health (48\%). In contrast, several years earlier $22 \%$ of faculty members surveyed by Sheridan et al. (1994) said curriculum in general courses contained content on spirituality or religion, and only $9 \%$ indicated that their school offered a separate course on spirituality or religion.

Dudley and Helfgott (1990) and Sheridan et al. (1994) studies provide a starting point for the current study. These studies investigated faculty attitudes toward spirituality and religion as they relate to social work, finding that most faculty members agree that spirituality is an aspect of being human, and is relevant to social work practice. They found mixed results regarding the role of a separate course in the 
curriculum on spirituality and religion as they relate to social work, with less opposition to a separate course in 1994 than in 1990. Since these studies were conducted, social work educators have become increasingly aware of the need for social work students to become familiar with spirituality in order to provide quality services to clients (Miller, 2001). As noted above, many universities now offer specific elective courses in spirituality and social work practice (Canda \& Furman, 1999; Ellor et al., 1999; Kilpatrick \& Puchalski, 1999), and programs have begun to incorporate discussion of spirituality in other courses in social work curriculum such as courses on diversity and human behavior in the social environment (Ai et al., 2004; Kilpatrick \& Puchalski, 1999).

The current study takes the next step by exploring the extent to which spirituality is currently incorporated into regular social work courses. This is the first study that asks faculty members if they include the topic of spirituality, if students bring up the topic, and what the outcomes of discussions regarding spirituality are. The focus of the study is on relationships among variables associated with inclusion of spirituality in social work. The study also replicates several variables from the previous studies; including items regarding faculty views of spirituality as an aspect of being human (Dudley and Helfgott, 1990; Sheridan et al., 1994), knowledge of client's religious or spiritual belief systems as important for effective social work practice (Sheridan et al., 1994), and support for a separate course on spirituality and religion in social work (Dudley and Helfgott, 1990; Sheridan et al., 1994). Also replicated are questions regarding current and childhood participation in religious services and personal spiritual practices (Sheridan et al., 1994). The inclusion of additional 
personal experience variables in the current research will allow expanded analysis of these items from previous studies.

Students at the University of Washington (Ai et al., 2004) initiated a survey of first-year students in their MSW program regarding the extent to which spirituality was included in specific courses in the curriculum and their satisfaction with the level of inclusion. Interestingly $65 \%$ of students said spirituality and $37 \%$ said religion was important in their personal lives. Fifty-two percent of students who responded to openended questions expressed a desire that spirituality be integrated into general foundational courses. Specific courses where students suggested incorporating spirituality were: Diversity, Practice classes, Human Behavior in the Social Environment, and a separate course on spirituality or religion (Ai et al., 2004).

Some differences between results of Dudley and Sheridan's studies may be due to different sampling frames: Dudley's sample included a small number of secular schools in the Northeast, while Sheridan's included a larger sample from Southeastern states, including some sectarian schools. The sampling frame for the current study represents all regions of the country, and includes only secular institutions to avoid possible sample bias toward religion. With a focus on examination of relationships between variables rather than generalization of findings, the sampling frame includes schools with the ability to offer a wide range of courses related to diversity, the primary variable of interest. US News and World Report ranks graduate programs in social work which reflect highly respected programs based on peer assessment surveys completed by deans, other administrators, and/or faculty at accredited degree programs or schools in social work (Morse \& Flanigan, 2007). These schools might be 
considered state-of-the-art in the estimation of program deans and senior faculty members, and are thought to represent exemplary teaching practices.

To summarize the above, the social work profession acknowledges a need for increased awareness and knowledge of issues related to spirituality in social work education in order to prepare social workers to better address the needs of clients for whom spirituality is important. Social work literature, however, documents a lack of coverage of this topic in social work journals and textbooks, along with neglect of this topic in social work education.

\section{Concerns Regarding Spirituality in Social Work Education}

Concern has been expressed about the feasibility and appropriateness of including the topic of spirituality, and particularly religion, in social work education. To be successful, the inclusion of spirituality must improve the education of social work students and their ability to relate with clients and community agencies, must be compatible with existing social work values and norms, and must not be so complex that it becomes difficult to teach. The social work curriculum is already full of important material to address (Clark, 1994a). Each additional topic takes time away from other topics in an already overflowing curriculum (Crocco, 2004). The inclusion of new material into an already established curriculum may understandably face resistance by faculty members.

Spirituality is a complex concept and can be difficult to understand and discuss (Ai, 2002). Clark (1994b), argues that there are so many different forms of religion that it would be impossible for social workers to become familiar with all of them. Dalton (2005) agrees that with the vast array of ethnic, cultural and spiritual groups 
present in our society, social work educators cannot possibly teach students to be appropriately sensitive to all groups that a clinician may come in contact with. He alternatively recommends teaching students to gather general information about the clients' worldview, spirituality, and significant relationships to gain a fuller understanding of their particular values and beliefs.

Some authors suggest that inclusion of religion in social work education would compromise social work values. Some social work educators fear that clients could be subjected to proselytizing by overzealous therapists (Miller, 2001). Others argue that to include spirituality or religion in social work practice would comprise a dual relationship, where the social worker is taking the role of a pastoral counselor (Miller, 2001; Clark, 1994). Another concern relates to value issues; when two different social work values conflict, which value takes precedence? The value of human diversity respects all groups in society equally; the value of social justice dictates that the rights of traditionally oppressed minorities take precedence over the rights of other groups (Applebaum, 2003). The value of self-determination of religious educational institutions may conflict with the value of freedom of speech as well as employment rights of sexual minorities (Van Soest, 1996). Dorothy Van Soest (1996) concludes that open acknowledgement of ideological differences within the profession of social work can lead to improved solutions to these value dilemmas.

As noted above, the organization responsible for setting policy in social work education, CSWE, recognizes religion as part of human diversity, and spirituality as part of human development, and that both have a role in social work education. The largest professional organization of social workers, the National Association of Social 
Workers (NASW), however, retains some skepticism about the role of religion in public life. This skepticism was most visible in their response to Charitable Choice legislation. Charitable Choice was a provision of the Personal Responsibility and Work Opportunity Reconciliation Act of 1996, allowing faith-based and community organizations to compete for federal grants for social service provision. NASW published several position statements expressing that while social workers have had a long and positive relationship with religious organizations, the faith-based initiative "may pose serious challenges to this historical relationship" (NASW, 2001; NASW, 2002b). One of the major challenges in the relationship between social workers and religious organizations is the issue of separation between church and state (NASW, 2001; NASW, 2002b; NASW, 2002c).

NASW strongly supports the constitutional principle of separation of church and state. NASW maintains that the expression of religious belief is a personal and private matter that should be neither constrained nor promoted by the government in any way. NASW opposes the use of tax policy, administrative regulations, or the distribution of government funds to support organized religion in any manner (NASW, 2001).

In the context of social work education, school administrators may be concerned that including content on spirituality or religion violates the barrier between church and state, particularly in public universities. Would coverage of content about religion as an aspect of spirituality be viewed as support for organized religion, or as promoting religion? The goal of inclusion of spirituality in social work education 
must focus on enhancing students' understanding of clients and community members' views and experiences, not influencing their beliefs (Miller, 2001; Sherwood, 2002). The topics of spirituality and religion may be resisted by social worker educators for philosophical reasons as well. As noted previously, social work as a discipline distanced itself from religion and spirituality in the process of establishing status as a profession, embracing scientific and rational methods of inquiry. Spirituality does not fit neatly into the scientific paradigm, and addresses aspects of life that are not observable or measurable. There is concern by some that by crossing the boundary between science and spirituality, social work could lose its' status as a respected profession (Clark, 1994b). 


\section{Theoretical Framework}

The theoretical basis for much of social work education today is critical theory, with its origin in neo-Marxist thought developed by the Frankfurt School in the 1920s (Saleebey \& Scanlon, 2005). Critical theory has been applied to education since the mid 1980s in the form of critical pedagogy, which draws from constructivist, social constructionist, ecosystems, structuralist and strengths perspectives (Gibbons \& Gray, 2004). Rather than viewing reality as consisting of universal, static truths, reality according to critical theory is viewed from the unique perspective of the individual or group and is dependent on their particular experience and perspective; “...reality is not an objective set of arrangements outside ourselves, but is constructed through a process of interaction in groups, communities, and cultures" (Littlejohn, 1992, p.163). Based on their experiences in life, "people create or make sense of their own realities" (Gibbons \& Gray, 2004, p. 23). This act of creating an understanding of reality is an iterative cycle; action followed by reflection, drawing conclusions from the experience, followed by action and more reflection in a process of trial and error (Gibbons \& Gray, 2004). Knowledge gained in this manner is not static, but always changing, growing as new experience leads to new knowledge or challenges previous knowledge. Due to the fluid nature of this knowledge it is important to be able to tolerate uncertainties, doubts, and ambiguity resulting from the process of knowledge acquisition. 
Personal beliefs and values naturally affect one's basic assumptions and interpretation of reality, and are important to be aware of and acknowledge.

Critical thinking, rather than claiming objectivity, is value-laden thinkingmuch more than common sense. We engage with the world and with others and our judgments, conclusions, ideas, and opinions flow from these interactions - never from a standpoint of detached objectivity. The importance is, therefore, to make our values, judgments and decision-making explicit, rather than to claim that they are not there and to see critical thinking as crucial to the process of constructing knowledge, meaning and understanding (Gibbons and Gray, 2004, p 37).

One important goal of critical pedagogy is to promote equality within relationships and social structures by changing power relationships that allow one individual or group to dominate others. Power structures within macro and micro environments are analyzed and ideas critiqued particularly in relation to issues of race, class and gender (Saleeby \& Scanlon, 2005). Gibbons and Gray (2004) describe the process involved in critical thinking:

The process of critical thinking...involves the experience of a challenging situation or issue, followed by the identification of assumptions or hypotheses about it, observation and refinement of the hypotheses, the application of reasoning and judgment, the development of alternative responses and finally taking action to respond to the situation (Gibbons \& Gray, 2004, p. 22). Within an educational setting, critical pedagogy involves expanding student's awareness of alternate perspectives by discussion of diverse, multicultural views. "We 
focus on the resources and capacities that each student brings to the group, the more diverse the group, the greater the potential for learning" (Gibbons \& Gray, 2004, p. 24). A dialogic model of teaching is used in which small group discussion is encouraged as a way for students to be actively engaged in expressing their own views and listening to the views of others in an environment where all views are respected and difference is valued (Saleebey \& Scanlon, 2005; Shor, 1996). "The giving and receiving of constructive feedback is crucial to the process of building and capitalizing on strengths within the classroom, to acceptance and tolerance of different interpretations and viewpoints, and to the development of critical thinking skills" (Gibbons \& Gray, 2004, p. 28). Saleeby and Scanlon (2005) outline elements involved in open discussion of diverse ideas.

We suggest that a dialogically centered classroom requires: (1) stimulating the perspectives of everyone in the classroom, and encouraging reflection on how these experiences are consistent and different from formal social work knowledge, (2) promoting discussions of cultural and class differences and similarities and sharing of experiences of domination and oppression, and (3) stimulating a healthy appreciation for ambiguity and disagreement in the classroom. (Saleeby \& Scanlon, 2005, p.13)

As noted above, a necessary condition for discussions involving diverse ideas is a classroom environment where students feel safe to express their opinions, understandings and questions without being attacked or humiliated by others. Parker Palmer (1990) addresses the issue of conflict in the college classroom, and points out that fear of conflict can act as a barrier to the type of open and honest discussion 
necessary for the most profound learning to take place. Palmer suggests that conflict can instead be viewed as a creative force which can either lead to competition in which someone wins and someone else loses, or can lead to consensus, in which: ...the clash of apparent opposites gives rise to fresh, fuller truth. A consensual classroom assumes that truth requires many views and voices, much speaking and listening, a high tolerance for ambiguity in the midst of a tenacious community. Consensual truth is not the outcome of majority vote. It is a continuing revelation that comes as we air our differences in public, pay special heed to those who dissent, and seek deeper insight... (Palmer, 1990). Contributing to the discussion of dealing with differences in constructive ways, James Davison Hunter (1991) addresses communication between people from different worldviews. In addition to fostering discourse which fully illuminates each point of view and encouraging all voices to enter the discussion, Hunter emphasizes the importance of understanding the vital components of each view; aspects of each position that are essential and non-negotiable to adherents. Respect for the core beliefs of another creates space for dialogue and understanding, while disrespect for these core beliefs creates mistrust and conflict. An equally important component in Hunter's model is the humility to recognize vulnerabilities or areas of blindness in our own point of view.

At this point it may be helpful to point out that differing definitions of respect may complicate the discussion. One definition of respect is "giving particular attention" (Webster's Seventh New Collegiate Dictionary, 1967), involving careful thought or taking something into account. An alternate definition of respect is "high or 
special regard" (Webster's Seventh New Collegiate Dictionary, 1967), involving esteem or honor. When dealing with disagreement between opposing views, high regard, esteem, or honor shown toward one view often requires rejection of the other, rather than respect. Keeping in mind, however, the principle of self-determination discussed above, which recognizes each person's right to hold views and beliefs consistent with their own convictions and understanding of truth, it is possible to show respect for another's view out of respect for the other person. Respect for views or beliefs which differ from or conflict with one's own involves giving careful thought and attention to the other's point of view. This understanding of respect is crucial to facilitate open discussions of diverse ideas in social work classrooms.

Several questions arise when applying critical pedagogy to multicultural populations, including issues related to spirituality and religion. First, ideas are evaluated primarily on the basis of power and equality; some cultural or ideological groups would argue that other values take precedence, and may not view their current power arrangements as problematic. Second, critical analysis emphasizes the importance of using classroom discussions to critique ideas, analyzing the impact they have on power relationships. Students may fear criticism and be reluctant to openly share true beliefs and assumptions if those beliefs will be challenged. Third, most major religions do not accept the idea that truth is relative and is socially constructed, but believe that truth is universal and transcends time. This leads to an important challenge for social work education: those coming from a critical perspective would interpret a person's spiritual faith as a social construction; the spiritual person would however understand their faith as a reflection of an external reality. The faculty 
member is faced with the difficult task of teaching tolerance for difference on the premise that all truth is socially constructed, while at the same time respecting that some students and many in the general population understand reality to be composed of truths that are universal and transcendent.

In summary, the full expression of critical pedagogy in social work classrooms opens up the potential to incorporate discussions of spirituality as a dimension of human experience. Aspects of critical pedagogy that can be especially helpful to faculty who want to incorporate spirituality into course curriculum are recognition of the role that values play in interpretation of experience; respect for different points of view held by students as well as the larger population they will encounter in social work practice; a focus on strengths and empowerment; and the larger concern for social justice; all of which are foundational values in the profession of social work. 


\section{Research Questions and Hypotheses}

This section outlines the eight research questions.

The initial two questions relate the present study to two previous surveys of faculty views on the role of spirituality in social work education. The first is a direct comparison of replicated items.

\section{Question 1}

Do views of faculty in the current study differ significantly from those of previous surveys regarding their support for a separate course on spirituality or religion in social work, and of spirituality as a fundamental aspect of being human?

The second question expands previous analysis of faculty views by adding personal affiliation, personal experience, and school environment variables as predictors.

Question 2

Do personal experiences with spirituality and school environment predict support for a separate course on spirituality, views of spirituality as an aspect of being human, and the relevance of client beliefs to clinical practice?

Hypothesis: Positive affiliation with friends and family who value spirituality, positive personal experience with spirituality, and school support for inclusion will predict support for a separate course on spirituality, views on spirituality as an aspect of being human, and the relevance of client beliefs to clinical social work practice.

As noted previously, the Educational Policy and Accreditation Standards of the Council on Social Work Education (Council on Social Work Education, 2001) state that social work educators need to prepare students to deal with issues of spirituality and religion in social work education. The next question asked in this study 
is whether faculty members are introducing spirituality as a topic in their courses.

Stated more precisely:

Question 3

What proportion of faculty members participating in the survey include content regarding spirituality in their courses, excluding courses specifically focused on spirituality or religion?

If sufficient data is available, Questions 4-8 will then be analyzed.

The fourth question examines the role of personal experience and school

environment variables in faculty inclusion of spirituality.

\section{Question 4}

What factors predict inclusion of spirituality by social work faculty?

Hypothesis: Faculty personal experience with spirituality, adequate educational preparation, school support for inclusion, student inclusion, classroom management strategies and nature of classroom discussion will predict faculty inclusion of spirituality in their courses, excluding courses specifically focused on spirituality or religion.

The fifth question focuses on factors hypothesized to be associated with

student inclusion of the topic of spirituality.

\section{Question 5}

What factors predict faculty experience of student initiation of spirituality as a topic in social work classes?

Hypothesis: Faculty inclusion of spirituality, classroom management strategies, constructive discussion, and lack of conflict will predict faculty experience of student inclusion of spirituality as a topic in social work classes.

Achieving the goal of respect for different views in the classroom, including spirituality, depends partly upon constructive classroom discussion regarding the topic. 


\section{Question 6}

What factors predict constructive learning experiences in social work classrooms?

Hypothesis: Faculty inclusion of spirituality, the use of rules, modeling, group facilitation skills, and student inclusion of spirituality will predict constructive classroom discussion about spirituality.

The next question examines factors related to inclusion for a specific subset of

faculty members.

\section{Question 7}

What factors predict inclusion of spirituality by faculty with little personal experience with spirituality?

Hypothesis: Adequate educational preparation, school support for inclusion, student inclusion, and positive affiliation with friends or family who value spirituality will predict inclusion of spirituality by faculty with little personal experience of spirituality.

The last question is exploratory, using data obtained in the above analyses.

\section{Question 8}

What overall model of relationships explains components necessary for constructive classroom discussion of spirituality? 


\section{Methods}

\section{Design, recruitment and procedures}

The study was a cross-sectional survey conducted via web survey. The survey was developed using WebSurveyor software, accessed through the Portland State University Office of Information Technology. The web-based survey invitation was emailed to faculty directly from the University server which also received, stored and managed the completed survey data in a secure location. Results of the survey were collected and stored separately from originating email addresses. One copy of the data was maintained in a confidential, secure location for the sole use of the researcher.

Faculty members were recruited from 22 fully accredited schools of social work identified in US News and World Reports' top-ranked Social Work programs in the United States. One additional university in the listing was identified as a sectarian school from their website, and was eliminated from consideration. Potential individual participants were located by searching school web sites for social work courses containing content related to diversity, human behavior in the social environment, and direct social work practice. This process led to the identification of 442 prospective participants. The survey protocol was based upon Dillman's mixed-mode method (Dillman, 2000, 2007; Rosenbaum \& Lidz, 2007), and recommendations by David Hodge (personal communication, May 27, 2006). The week of October 5, 2007, the identified faculty members were contacted by telephone. They received a short message on their office answering machine inviting them to participate in a doctoral student survey, informing them that they would receive an email with more 
information which contained the survey (Appendix A). On October 11, faculty

members received the first email with a short explanation of the purpose of the survey and links to the cover letter, which included more detailed information about the survey (Appendix B). Faculty members then could click on a button stating, "I agree to participate," which allowed them access to the survey, which could be completed and submitted electronically. Also on October 11 and October 13, a card was mailed to the faculty members' school address with a $\$ 5$ gift card to Starbucks as a thank-you to those who had completed the survey, and a complimentary gift for those who have not yet taken the survey. Faculty who did not respond to the initial email were recontacted by email on October 18, and October 25, 2007 with invitations to participate. Completed surveys were received from 222 faculty members out of 442 email recipients; with 11 returned as undeliverable, the response rate was $52 \%$.

\section{Sample demographics}

Participants were mostly female, with $33.8 \%$ males; $3.6 \%$ did not give their gender. Table 1 contains basic demographic information. Most faculty members had a $\mathrm{PhD}$ in Social Work (63.1\%), were teaching full-time (68\%), and had been teaching an average of 13 years, with a median of 10 and mode of 20 years. Faculty members' average age was 50.4 years, with concentrations at 55 and 60 .

The ethnic makeup of the sample was mostly identified as EuroAmerican/White (76\%), with 6.3\% African-American/Black, and 5.4\% Latino/Hispanic-American (please refer to Table 2). A majority of faculty surveyed identify with a spiritual orientation of some kind (please refer to Table 3). Only $26 \%$ of the sample describe themselves as agnostic, atheist, or otherwise non-spiritual. This 
is likely a low estimate however, considering that an unknown number of faculty members in the Jewish-Other category have a cultural, rather than religious identification with Judaism, and that faculty who are not interested in spirituality might be less likely to complete the survey.

Table 1

Demographic Information $(N=222)$

\begin{tabular}{lrrr}
\hline Variable & $N$ & $\%$ & $S D$ \\
\hline Gender & & & \\
$\quad$ Female & 139 & 62.6 & \\
Male & 75 & 33.8 & \\
Not reported & 8 & 3.6 & \\
Age $\quad$ & 50.42 & & 10.07 \\
$\quad$ Mean & 51 & & \\
Median & 55 & & \\
Mode & & & \\
Years teaching & 13.22 & & \\
Mean & 10 & & \\
Median & 20 & & \\
Mode & & & \\
Degree & 140 & 63.1 & \\
PhD & 64 & 28.8 & \\
MSW & 18 & 8.1 & \\
Other degree & & & \\
Tenure & 62 & 27.9 & \\
Tenured & 61 & 27.5 & \\
Tenure-track & 99 & 44.6 & \\
Non tenure track & 151 & 68 & \\
Full time status & &
\end{tabular}

${ }^{1}$ Multiple modes exist. The smallest value is shown. 
Table 2

Ethnicity

\begin{tabular}{lrr}
\hline Ethnic Identification & $N$ & $\%$ \\
\hline African-American/Black & 14 & 6.3 \\
Asian-American/Pacific Islander & 7 & 3.2 \\
Bi-racial/Multi-racial & 7 & 3.2 \\
Euro-American/White & 169 & 76.1 \\
Latino/Hispanic-American & 12 & 5.4 \\
Native-American/Alaskan Native & 2 & 0.9 \\
Other & 7 & 3.2 \\
Missing & 4 & 1.8 \\
\hline
\end{tabular}

Table 3

Spiritual Orientation

\begin{tabular}{lccc}
\hline Category & $N$ & $\%$ & Cum \% \\
\hline Non-spiritual & & & 26.2 \\
None & 13 & 5.9 & \\
Agnostic & 18 & 8.1 & \\
Atheist & 17 & 7.7 & \\
Other: non-spiritual & 10 & 4.5 &
\end{tabular}

Spiritual

Buddhist

$\begin{array}{ll}7 & 3.2\end{array}$

Existentialist

$\begin{array}{ll}6 & 2.7\end{array}$

Unitarian Universalist

$10 \quad 4.5$

Other: spiritual

27

12.2

Jewish

Jewish-Conservative

Jewish-Orthodox

Jewish-Reform

Jewish-Other

Christian

Christian-Catholic

Evangelical Protestant

Mainline Protestant

Christian-Other

$\begin{array}{rr}5 & 2.3 \\ 1 & 0.5 \\ 9 & 4.1 \\ 16 & 7.2\end{array}$

14.1

2.3

4.1

7.2

37.5

$26 \quad 11.7$

$5 \quad 2.3$

$41 \quad 18.5$

$11 \quad 5$


To better understand how beliefs of the current sample relate to those of the general population, data from the current study is compared with that of 35,556

Americans from a study conducted by the Pew Forum on Religion and Public Life; the Religious Landscape Study (2007) in Table 4 below. It appears that faculty members were more likely to be Agnostic, Atheist, or affiliated with non-traditional spiritualities than the general population, and less likely to be Evangelical Protestant or Catholic.

Table 4

Spiritual Identification: Social Work Faculty compared with United States General Population

\begin{tabular}{lcc}
\hline Category & $\begin{array}{c}\text { Faculty } \\
\%\end{array}$ & $\begin{array}{c}\text { General } \\
\text { Population }{ }^{2} \%\end{array}$ \\
\hline None & 5.9 & 6.3 \\
Agnostic & 8.1 & 2.4 \\
Atheist & 7.7 & 1.6 \\
Other & 4.5 & 6.3 \\
Buddhist & 3.2 & 0.7 \\
Existentialist & 2.7 & - \\
Unitarian Universalist & 4.5 & 0.7 \\
Other- spiritual & 12.2 & 7.8 \\
Jewish-Conservative & 2.3 & 0.5 \\
Jewish-Orthodox & 0.5 & 0.3 \\
Jewish-Reform & 4.1 & 0.3 \\
Jewish-Other & 7.2 & 0.7 \\
Christian-Catholic & 11.7 & 23.9 \\
Evangelical Protestant & 2.3 & 26.3 \\
Mainline Protestant & 18.5 & 18.1 \\
Christian-Other & 5 & 10.2 \\
\hline${ }^{1}$ Wuest dissertation (2007) & & \\
${ }^{2}$ Pew Forum on Religion and Public Life Religious Landscape \\
Study (2007) & &
\end{tabular}




\section{Measures}

The survey instrument is composed of 40 questions with four major sections; general information, classroom management strategy, classroom inclusion of spirituality, and personal experience with spirituality (see Appendix A). General information, demographics and items regarding faculty views about spirituality and religion, and personal spirituality were developed by Michael Sheridan and colleagues for use in their 1994 survey of faculty members. Items regarding classroom management strategies, faculty and student inclusion of spirituality, discussion outcomes, and positive affiliation are original to the current study. Demographic variables include years teaching at a university level, teaching position, program, degree held, age, gender, ethnicity, and religious affiliation.

Seven primary variables are studied: Faculty inclusion of spirituality, student inclusion of spirituality, classroom management strategies, outcome of classroom discussion of spirituality, school support for inclusion of spirituality, faculty preparedness to address spirituality, and personal experience of spirituality.

Faculty inclusion of spirituality is measured with a dichotomous item about the presence of spirituality in their syllabus, readings, or lectures, and with a continuous item measuring frequency of inclusion in lectures, textbooks or other assigned readings. Student inclusion of spirituality is measured by items measuring faculty perceptions of the extent to which students bring up issues of spiritual diversity in class discussion, individually with faculty, or in written assignments.

Classroom management strategies examined are classroom rules for respectful discussion, modeling acceptance of diversity, and active facilitation of classroom 
dynamics. Two possible outcomes of classroom discussion about spirituality are measured: constructive learning experiences, and conflict or heated discussion.

School support for inclusion of spirituality is measured by the existence of a course on spirituality and/or religion in the social work curriculum, and faculty members' awareness of other faculty members who include spirituality in their courses. Faculty preparedness to address spirituality is measured by three items: a rating of their sense of preparedness, the presence of content on religion and spirituality in their own graduate social work education, and their satisfaction with this education. Personal experience with spirituality is measured with items regarding religious affiliation, current and childhood participation in religious services, and current spiritual practices such as meditation or prayer.

\section{Scale Development}

Item distributions and correlations were analyzed through reliability and factor analysis for scale development. Following is a detailed account of scale formation.

Faculty inclusion of spirituality. The initial measure of faculty inclusion of spirituality was a question asking if the topic of spirituality is present in their course syllabus, readings, or lectures $(\mathrm{No}=23.9 \%$, Yes $=76.1 \%)$. Those who responded Yes were asked to indicate how frequently spirituality was included in lectures, textbooks and in assigned readings, using a 0-6 point scale. Inclusion in lectures $(M=4.3, S D=$ $1.32)$, in textbooks $(M=2.9, S D=1.75)$, and in assigned readings $(M=3.9, S D=$ 1.49) were highly correlated (see Table 5 below). 
Table 5

Item Correlations: Faculty Inclusion of Spirituality

\begin{tabular}{lrc}
\hline & Lectures & Textbooks \\
\hline Textbooks & $.69^{* *}$ & \\
Assigned readings & $.83^{* *}$ & $.68^{* *}$ \\
\hline$* * p<.001$ & &
\end{tabular}

The three items were combined in a scale; cases indicating no course content on spirituality were entered as zero on the scale. Missing values were imputed through regression. Cronbach's Alpha for the faculty inclusion scale indicates very good reliability, $\alpha=.89$, and a factor analysis found one component, accounting for $82 \%$ of the variance. The distribution of the faculty inclusion scale is normal with the exception of a large number of faculty who did not include spirituality $(N=53)$; Mean $=8.4$, Median $=10$, and Mode $=0, S D=5.69$.

Student inclusion of spirituality. Student inclusion of spirituality was measured by three items using 0-6 point scales; student initiated discussion in class $(M=3.1, S D$ $=1.40)$, individual consultation with professor $(M=2.1, S D=1.48)$, and content in written assignments $(M=3.0, S D=1.50)$. These three items were highly correlated (see Table 6 below). Values for missing data were imputed through regression.

Table 6

Item Correlations: Student Inclusion of Spirituality

\begin{tabular}{lcc}
\hline & Student discussion & Consultation \\
\hline Consultation & $.47^{* *}$ & \\
Essays & $.58^{* *}$ & $.52 * *$ \\
\hline$* * p<.001$ & &
\end{tabular}


Cronbach's Alpha for the student inclusion scale indicates good reliability, $\alpha=.76$, and a factor analysis found one component, accounting for $68 \%$ of the variance. The distribution of the student inclusion scale is normal; Mean $=8.2$, Median $=8$, and Mode $=9, S D=3.60$.

Classroom management strategies. Classroom management strategies were measured in three ways using 0-6 point scales; classroom rules for respectful discussion $(M=4.9, S D=1.71)$, modeling acceptance of diversity $(M=5.6, S D=$ $.65)$, and active facilitation of classroom dynamics $(M=5.5, S D=.79)$. Cronbach's Alpha for rules, modeling, and facilitation $(\alpha=.56)$ is not adequate for scale construction (Aiken, 1996). A high correlation between modeling and facilitation $(r=.63)$ raises the likelihood of multicollinearity in analyses, therefore the two variables were combined. The new modeling and facilitation variable was highly skewed (-3.161); transformations were attempted, did not improve the distribution or significantly change the strength or direction of relationships in regression. For the purposes of analyses, the non-transformed combination of modeling and facilitation will be used, as skewness does not negatively affect estimation of variance with samples of at least 200 (Tabachnick and Fidell, 2001).

Outcomes of classroom discussion. Two aspects of classroom discussion were measured using 0-6 point scales: constructive learning experiences $(M=4.6, S D=$ $1.17)$, and conflict or heated discussion $(M=2.2, S D=1.45)$. These two items do not correlate with each other and will be entered separately in analyses.

School support for inclusion of spirituality. School support was originally measured by two items. The first asked if the faculty members' school currently offers 
a separate course on social work and spirituality and/or religion $(\mathrm{No}=43.2 \%$, Yes $=$ $48.6 \%, 18$ missing). The second variable asked if, to their knowledge, other faculty members incorporate spirituality into their classes with responses on a 0-6 point scale (always/never, don't know) $(M=5.0, S D=2.72$; don't know $N=64)$. Neither of these variables is stable or meaningful due to greater than $5 \%$ missing data, and will not be used in the analysis. A new variable was constructed to answer the same question, indicating which schools offer a course in spirituality using information obtained from course schedules on each school website. This information was supplemented with information from survey items which asked faculty to indicate which courses they teach, which identified nine faculty members teaching courses with the terms religion or spirituality in them.

Course schedules for five of the schools did not include a course in spirituality and social work, while several faculty members from each school indicated that there was a separate course. There are several possible explanations for this. Elective courses may be offered less than once a year and not be found in one particular course schedule. Courses with titles such as Complementary, Alternative and Indigenous Healing, and Theory and Practice of Mind-Body Connections for Self-Care and Clinical Application may include the topic of spirituality even though it is not in the course title. A decision was made to consider a school as including spirituality if at least three faculty responders from a school indicated that there was such a course (at least a third of total responders from a particular school). Using this method, all five schools met the criteria; a total of seventeen of the twenty-two schools were identified as offering a course in spirituality and social work. 
Rather than attempting to measure the broader and less well-defined concept of school support as originally planned, the more concrete item measuring the presence of spirituality in the school curriculum will be used to represent a school culture or environment which includes the topic of spirituality.

Faculty preparedness to address spirituality. Faculty preparedness to address spirituality was measured with three items on 0-6 point scales: when spirituality becomes the topic of discussion in your classes, how prepared are you to discuss this topic $(M=4.6, S D=1.19)$; in your own graduate social work education and training, content on spirituality and religion was presented almost never/almost always $(M=1.3, S D=1.44)$; and rate your satisfaction with the amount of content on spirituality and religion included in your own graduate education $(M=3.0, S D=$ 1.76). Both satisfaction and sense of preparation are highly subjective items, and a negative correlation between satisfaction and sense of preparation make the items difficult to interpret. As noted in Table 7 below, correlations between the three variables are fairly low; and reliability is extremely low $(\alpha=.10)$. It was decided that the more concrete measure, content in own education, will represent faculty preparation in analyses.

Table 7

Correlations of faculty preparedness variables

\begin{tabular}{lcc}
\hline & Feels prepared & Own Education \\
\hline Own Education & $.135 *$ & \\
Satisfaction with Education & $-.321 * *$ & $.241^{* *}$ \\
\hline$* p<.05,{ }^{* *} p<.001$ & &
\end{tabular}


Personal experience with spirituality. Personal experience with spirituality was measured by 7 items: Current attendance and childhood attendance at religious services, current spiritual practices such as meditation or prayer, and level of participation and involvement in organized spiritual or religious group are categorical variables and are summarized in Tables 8 and 9 on the next page. Reaction to past religious experience was measured on a $0-6$ point scale (very negative/very positive) $(M=3.6, S D=1.67)$ (see distribution in Figure 3 on next page). The number of friends or family members who value spirituality was measured on a $0-6$ point scale (none to more than five friends or family members) $(M=5.3, S D=1.25)$. The distribution of friends value spirituality was skewed, with seventy percent of faculty members reporting more than five friends who value spirituality. Relationship with friends who value spirituality was measured on a 0-6 point scale (very negative to very positive $)(M=5.48, S D=0.81)$ and was similarly skewed, with $91.8 \%$ of the sample reporting positive relationships.

A reliability analysis was conducted with all 7 items; please see intercorrelation matrix in Table 10. Cronbach's Alpha $(\alpha=.70)$ shows good reliability (Aiken, 1996). Removal of childhood attendance improves alpha to $(r=.72)$. A factor analysis showed two components, the first containing the bulk of the variables with the exception of childhood attendance, friends value spirituality, and relationship with friends who value spirituality, the second component primarily contained the two friend variables. A second reliability analysis was performed with items identified in component one of the factor analysis, current attendance, current spiritual practices, reaction to past experience, and level of participation and involvement. Cronbach's 
Alpha $(\alpha=.74)$ was improved, and factor analysis confirmed one component which explains $64 \%$ of the variance. These variables were combined to form the personal experience scale. Results of the factor analysis as well as examination of the remaining personal experience variables suggest that childhood attendance is not a necessary component of personal experience and that the remaining variables explain both a faculty members' reaction to childhood attendance and their current relationship with spirituality. Friends who value spirituality and relationship with friends or family who value spirituality will be entered into analyses separately.

Table 8

Frequency of Attendance at Religious Services

\begin{tabular}{lcc}
\hline Frequency & $\begin{array}{c}\text { Childhood } \\
\text { Attendance }(\%)\end{array}$ & $\begin{array}{c}\text { Current } \\
\text { Attendance }(\%)\end{array}$ \\
\hline Not at all & 9.0 & 28.8 \\
Less than once/yr & 3.2 & 6.8 \\
Once a year & 3.2 & 5.9 \\
Several times/yr & 10.8 & 24.8 \\
Once a month & 1.8 & 6.8 \\
2-3 times/month & 6.8 & 9.5 \\
Nearly every wk & 21.6 & 8.1 \\
Every week & 29.7 & 8.1 \\
More than once/ wk & 14.0 & 1.4 \\
\hline
\end{tabular}


Table 9

Current Spiritual Practices and Current Participation and Involvement

\begin{tabular}{lll}
\hline Frequency & $N$ & $\%$ \\
\hline
\end{tabular}

Frequency of current spiritual practices, such as meditation, prayer, and reading spiritual texts

Never

Only on certain occasions

Once a month

Several times/month

Nearly every week

Once a week

Several times/wk

Daily

Several times a day

$31 \quad 14$

$\begin{array}{ll}62 & 27.9\end{array}$

$13 \quad 5.9$

$21 \quad 9.5$

$8 \quad 3.6$

20.9

$36 \quad 16.2$

$36 \quad 16.2$

$13 \quad 5.9$

Current participation and involvement

Negative reaction to spiritual or religious tradition

No identification, participation, or involvement

Identification, very limited or no

involvement

$8 \quad 3.6$

Regular participation, some involvement Active participation, high level of involvement
$64 \quad 28.8$

57

$72 \quad 32.4$

25.7

$19 \quad 8.6$


Table 10

Personal Experience Correlations

\begin{tabular}{|c|c|c|c|c|c|c|}
\hline & 1 & 2 & 3 & 4 & 5 & 6 \\
\hline 1. Current attendance & $\ldots$ & & & & & \\
\hline 2. Childhood attendance & $.26 * *$ & - & & & & \\
\hline 3. Spiritual practices & $.47 * *$ & $.19 * *$ & - & & & \\
\hline 4. Participation/ involvement & $.81 * *$ & $.19 * *$ & $.45^{* *}$ & - & & \\
\hline $\begin{array}{l}\text { 5. Reaction to past religious } \\
\text { experiences }\end{array}$ & $.51 * *$ & $.22 * *$ & $.26 * *$ & $.52 * *$ & & \\
\hline 6. Friends value spirituality & $.30 * *$ & .11 & $.26 * *$ & $.21 * *$ & $.27 * *$ & - \\
\hline 7. Relationship with friends & $.14^{*}$ & .10 & .05 & .13 & $.25 * *$ & $.22 * *$ \\
\hline
\end{tabular}

Analysis

Assumptions were examined using SPSS Regression and SPSS Frequencies. Bivariate correlations and scatterplots, Mahalanobis distance, standardized residual scatterplots, residual histograms and normal P-P Plots were examined to assure that assumptions of normality, linearity, and homoscedasticity were met. Deviations from normality will be further discussed in the Results section. 


\section{Results}

The following details survey results relevant to each research question.

\section{Question 1}

Do views of faculty in the current study differ significantly from those of previous surveys regarding their support for a separate course on spirituality or religion in social work, and of spirituality as a fundamental aspect of being human?

Views of faculty members in the current study were compared to those found by Sheridan et al. (1994), and Dudley and Helfgott (1990) (see Table 11). Using ChiSquare through a web-based statistics calculator (Kirkman, 1996), categories were collapsed to compare responses: support for a separate course in spirituality/do not support course; and support for a required /elective course. There was significantly

more support for a separate course in the current study than in Sheridan's study, $x^{2}(1)$ $=26.5, p=.001 ;$ and more support in Sheridan's than Dudley's study, $x^{2}(1)=4.92, p$ $<.05$. Further examination of levels of support for a separate course showed Sheridan's sample to be more likely to vote for a required course than the current sample, $x^{2}(1)=12.0, p=.001$.

Table 11

Comparison of Vote for Separate Course in Spirituality Across Three Studies

\begin{tabular}{lrrrrrr}
\hline & Wuest (2007) & \multicolumn{2}{c}{$\begin{array}{l}\text { Sheridan (1994) } \\
(\mathrm{N}=220)\end{array}$} & \multicolumn{2}{c}{$\begin{array}{c}\text { Dudley (1990) } \\
(\mathrm{N}=51)\end{array}$} \\
\hline Do not support course & 5 & $2 \%$ & 44 & $16 \%$ & 15 & $29 \%$ \\
Support as elective & 190 & $86 \%$ & 171 & $63 \%$ & 32 & $62 \%$ \\
Required for all & 20 & $9 \%$ & 38 & $14 \%$ & 4 & $8 \%$ \\
Required for clinical & 5 & $2 \%$ & 17 & $6 \%$ & - & - \\
\hline
\end{tabular}




\section{Question 2}

Do personal experiences with spirituality and school environment predict support for a separate course on spirituality, views of spirituality as an aspect of being human, and the relevance of client beliefs to clinical practice?

Dependent variable: support for a separate course (yes/no)

Independent variables:

- Personal experience with spirituality

- Friends who value spirituality

- School offers a course in spirituality

- Student inclusion of spirituality

Dependent variable: type of course (elective/required)

Independent variables:

- Personal experience

- Friends who value spirituality

- School offers a course in Spirituality

- Student inclusion of spirituality

Dependent variable: spirituality as an aspect of being human

Independent variables:

- Personal experience

- Friends who value spirituality

- School offers a course in spirituality

Dependent variable: relevance of client beliefs to clinical practice

Independent variables:

- Personal experience

- Friends who value spirituality

- School offers a course in spirituality

The first part examines predictors for vote for a separate course on spirituality,

using the two dichotomous outcome variables created for the previous analysis:

support for a separate course (yes/no); and type of course (elective/required course).

These variables were entered into logistic regressions with predictors personal

experience scale, friends who value spirituality, and school offers a course in

spirituality. 
Correlations were examined using SPSS to determine relationships between predictors (personal experience scale, friends who value spirituality, and school offers a course in spirituality), demographic variables (age, gender, ethnicity, years teaching, degree, part or full time status, tenure), and one logically related covariate (student inclusion). Before running the multivariate analysis, some data reduction of independent variables was conducted. The demographic variables age and years teaching were highly correlated, $r=.67, p<.01$. The correlations of age and years teaching with other predictors showed multiple variables significantly correlated with years teaching. To reduce both collinearity and multicollinearity, age rather than years teaching was used in analyses as the primary time variable, for both statistical and theoretical reasons.

Data reduction of work status variables was also conducted. Tenure correlates positively with degree held, $r=.29, p<.01$, and with full or part time status, $r=.38$, $p<.01$, and degree held correlates with full or part time, $r=.48, p<.01$. Full or part time status shares considerable variance with both variables, and to reduce redundancy will represent faculty members' academic experience in the equation.

Only five participants indicated that they would vote against a course. A logistic regression for the dichotomous variable support for a separate course (yes/no) is therefore not feasible due to insufficient cell counts.

There was very little ethnic or racial diversity in this sample; African American/Black $(N=14)$, Latino/Hispanic-American $(N=12)$ and all other minority groups $(N=23)$. Predictably, cell counts were insufficient for logistic regression. 
Ethnicity was therefore dichotomized, comparing Euro-American/White to all other ethnicities.

To test the assumption of a linear relationship between continuous predictors and the DV, the full model was run using SPSS logistic regression including interaction terms of each continuous variable with its natural $\log$ (Tabachnick \& Fidell, 2001). No significant interactions were found, confirming linearity.

Demographic variables age, gender, ethnicity, full or part time status, predictors personal experience, friends who value spirituality, and school offers a course in spirituality, and covariate student inclusion of spirituality were entered simultaneously in a logistic regression analysis with the dichotomous outcome variable support for a course (elective/required) in spirituality, using SPSS.

Data from 198 faculty members were available for analysis: 174 voted for an elective in spirituality; 24 voted for a required course for students, either for all students or for students in the clinical track. A test with the above predictors against a constant only model was statistically significant, $X^{2}(8, N=198)=17.64, p<.05$. The Nagelkerke $R^{2}=.16$ indicating around $16 \%$ of the variance accounted for by this combination, keeping in mind that the Nagelkerke $R^{2}$ underestimates the association between multiple independent variables and the dependent variable (Hosmer \& Lemeshow, 2000). The Hosmer and Lemshow goodness of fit test, where a nonsignificant chi-square indicates good fit, confirms that the model as a whole fits the data well, $X^{2}=8.16$, n.s.

Please see Table 12 below for regression results. Variables that distinguished between faculty members who voted for required course and those who voted for an 
elective course were part-time status of the faculty and ethnicity. Odds ratios indicate that full time faculty were 3.8 times less likely than part time faculty, and ethnic minorities were 3.2 times more likely than Caucasians to vote for a required course.

Table 12

Logistic Regression Predicting Support for Required Course in Spirituality

\begin{tabular}{lcccc}
\hline Variable & $B$ & $S E B$ & Wald Test & $\begin{array}{c}\text { Odds } \\
\text { Ratio }\end{array}$ \\
\hline Age & .03 & .02 & 1.77 & 1.03 \\
Ethnicity & 1.17 & .53 & $4.93 *$ & 3.22 \\
Female gender & -.25 & .49 & .26 & .78 \\
Full-time & -1.33 & .48 & $7.62 * *$ & .26 \\
Student inclusion & .11 & .07 & 2.70 & 1.12 \\
Personal experience & .06 & .04 & 2.31 & 1.06 \\
School offers course & .49 & .58 & .71 & 1.64 \\
Spiritual friends & -.13 & .22 & .36 & .88 \\
\hline
\end{tabular}

$* p<.05, * * p<.01$

Question 2 also asks whether personal experiences with spirituality and school environment predict views of spirituality as an aspect of being human, and the relevance of client beliefs to clinical practice. A standard multiple regression was performed predicting faculty views of spirituality as an aspect of being human from personal experience, friends who value spirituality, and school offers a course in spirituality controlling for age, ethnicity, full time status and gender.

Bivariate scatterplots revealed one outlier with a low value for spirituality as an aspect of being human (score $=1$ ), and a high value for personal experience (score $=22$ ). A check of residual $z$-scores from an initial regression run confirmed the outlier, so this case was removed from analysis. Eighteen cases had missing values, $N=203$. 
Collinearity diagnostics were in the normal range with the Condition Index, $C I=$

24.38. Tolerances range from .967 to .870 .

Table 13 displays regression coefficients, significance tests, and significance levels. The model as a whole was significant, predicting $29 \%$ of the variance, $R=.54$, $F(7,195)=11.36, p<.001$. Four individual variables were significant predictors of faculty's views on spirituality as an aspect of being human: personal experience, friends who value spirituality, age, and ethnicity.

Table 13

Standard Multiple Regression Predicting Faculty Views of Spirituality as an Aspect of Being Human

\begin{tabular}{lccc}
\hline Variable & $B$ & SE B & $\beta$ \\
\hline Age & .03 & .01 & $.22 * *$ \\
Female gender & -.06 & .18 & -.02 \\
Full-time & .09 & .18 & .03 \\
Ethnicity & .44 & .21 & $.13 *$ \\
Personal experience & .09 & .01 & $.39 * *$ \\
School offers course & .14 & .21 & .04 \\
Spiritual friends & .17 & .07 & $.15^{*}$ \\
\hline
\end{tabular}

$* p<.05, * * p<.01$

A second standard multiple regression predicting faculty views of knowledge of spirituality as important for social work education was not feasible due to nonnormality of the dependent variable and weak correlations with hypothesized predictors. Personal experience $(r=.14, p=.05)$, and non-tenured faculty $(r=-.14, p$ $=.05)$ both had significant bivariate correlations with faculty views of knowledge of spirituality as important for social work. 


\section{Question 3}

What proportion of faculty members participating in the survey include content regarding spirituality in their courses, excluding courses specifically focused on spirituality or religion?

Nine faculty members were identified as teaching courses directly related to spirituality and were omitted from this analysis. Courses titles included Spiritual Aspects of Social Work Practice, Spirituality and Psychodynamic Practice, Spirituality and Social Work Practice, Introduction to World Religions, Spirituality and Healing, and Introduction to Spirituality and Social Work in Korea.

The vast majority, $75.1 \%$, of the remaining 213 faculty members stated that content on spirituality was included in the syllabus, readings, or lectures of courses they teach. Asked to identify up to three of their courses and to what extent spirituality is a topic in each course, faculty members reported having either a moderate or substantial discussion about spirituality in $53 \%$ of courses listed (see Table 14).

\section{Table 14}

Degree to which spirituality is included in social work courses

\begin{tabular}{lrc}
\hline & $N$ & $\%$ \\
\hline None & 15 & 4 \\
Mentioned & 46 & 12 \\
Brief discussion & 123 & 31 \\
Moderate discussion & 163 & 41 \\
Substantial discussion & 48 & 12 \\
\hline Total $N=395$ courses & &
\end{tabular}

A correlational analysis comparing the 53 faculty members who do not include spirituality in their courses with other faculty members indicated that faculty members who do not include spirituality are more likely to be male $(r=-.21, p<.01)$, are less 
likely to have personal experience with spirituality $(r=-.16, p<.05)$, and that students are much less likely to bring up the topic of spirituality $(r=-.45, p<.01)$ and are less likely to have constructive discussions about spirituality $(r=-.25, p<.01)$ in their classes.

Question 4

What factors predict inclusion of spirituality by social work faculty?

Dependent variable: faculty inclusion of spirituality

Independent variables:

- Personal experience with spirituality

- Content in own education

- School offers a course in spirituality

- Student inclusion of spirituality

- Constructive classroom discussion

- Conflictual classroom discussion

Faculty personal experience with spirituality, educational preparation, school offers a course, student inclusion, and constructive and conflictual classroom discussion were entered into a standard multiple regression as predictors for faculty inclusion of spirituality in their courses, excluding courses specifically focused on spirituality or religion. The nine faculty members identified above as teaching courses directly related to spirituality were omitted from this analysis. Thirty-three additional cases had missing values, resulting in a total of 180 cases for analysis.

The model as a whole was significant, predicting $33 \%$ of the variance in faculty inclusion of spirituality, $R=.57, F(10)=8.12, p<.001$. Tolerances range from .742 to .949 . Five individual variables were significant predictors of faculty inclusion of spirituality: student inclusion, constructive discussions, school offers separate course, female gender, and full time status, (See Table 15). 
Table 15

Standard Multiple Regression Predicting Faculty Inclusion of Spirituality

\begin{tabular}{lccc}
\hline Variable & $B$ & SE B & $\beta$ \\
\hline Personal experience & .05 & .06 & .06 \\
School offers course & -2.32 & .82 & $-.19^{* *}$ \\
Content in own education & -.09 & .24 & -.02 \\
Student inclusion & .54 & .12 & $.33 * *$ \\
Constructive discussions & 1.04 & .31 & $.23 * *$ \\
Conflictual discussions & -.28 & .25 & -.08 \\
Age & -.00 & .04 & -.00 \\
Female gender & 1.89 & .73 & $.17 * *$ \\
Full-time & 1.52 & .74 & $.13 *$ \\
Ethnicity & -.97 & .84 & -.08 \\
\hline
\end{tabular}

$* p<.05, * * p<.01$

Personal experience was not significant in the model but had a significant bivariate correlation with faculty inclusion of spirituality, $r=.17, p<.05$, as did use of rules, $r=$ $.17, p<.05$.

Question 5

What factors predict faculty experience of student initiation of spirituality as a topic in social work classes?

Dependent variable: student inclusion of spirituality Independent variables:

- Faculty inclusion of spirituality

- Use of classroom rules for respectful discussion

- Use of modeling acceptance of diversity

- Use of facilitation of classroom dynamics

- Constructive classroom discussion

- Conflictual classroom discussion

Faculty inclusion of spirituality, classroom management strategies, constructive discussion, and conflictual discussion were entered into a standard multiple regression predicting faculty experience of student inclusion of spirituality 
(student inclusion) as a topic in social work classes, controlling for age, gender, ethnicity, and full time status.

Mahalanobis distance indicated the presence of one outlier, which was removed, and thirty-one cases had missing values, resulting in a total of 190 cases for analysis. The model as a whole was significant, predicting $38 \%$ of the variance in faculty-perceived student inclusion of spirituality, $R=.61, F(9)=12.06, p<.001$.

Original regression runs showed consistently low tolerances for classroom management strategies modeling and facilitation, which have a bivariate correlation $r=.52, p<.01$. In order to reduce multicollinearity, modeling and facilitation were combined to form one twelve-point scale. Collinearity diagnostics were high, with Condition Index, $C I=53.32$ however no variable had more than one value greater than $.50(C I>30$ with two variables with two values over .50 indicate problematic collinearity). Tolerances range from .759 to .961 .

Four individual variables were significant predictors of student inclusion of spirituality according to faculty members: faculty inclusion, conflictual discussions, constructive discussions, and use of classroom rules, (See Table 16). Female gender was not significant in the model but had a significant bivariate correlation with student inclusion of spirituality, $r=.14, p<.05$. 
Table 16

Standard Multiple Regression Predicting Student Inclusion of Spirituality

\begin{tabular}{lccc}
\hline Variable & $B$ & SE B & $\beta$ \\
\hline Faculty inclusion & .22 & .04 & $.35 * *$ \\
Use of classroom rules & .30 & .14 & $.14 *$ \\
Use of modeling and facilitation & -.20 & .24 & -.06 \\
Constructive discussions & .68 & .19 & $.24 * *$ \\
Conflictual discussions & .56 & .14 & $.25 * *$ \\
Age & -.01 & .02 & -.03 \\
Female gender & .39 & .43 & .06 \\
Full-time & -.08 & .44 & -.01 \\
Ethnicity & -.47 & .50 & -.06 \\
\hline
\end{tabular}

$* p<.05, * * p<.01$

Question 6

What factors predict constructive learning experiences in social work classrooms?

Dependent variable: constructive classroom discussion Independent variables:

- Faculty inclusion of spirituality

- Use of classroom rules for respectful discussion

- Use of modeling and facilitation

- Student inclusion of spirituality

Faculty inclusion of spirituality, the use of rules, modeling, group facilitation

skills, and student inclusion of spirituality were entered into a standard multiple regression predicting constructive classroom discussion about spirituality, controlling for age, gender, ethnicity and full time status.

Mahalanobis distance revealed two outliers which were confirmed by scatterplots, however their removal did not affect results so the complete sample was used. Twenty-nine cases had missing values resulting in a total of 193 cases for analysis. The model as a whole was significant, predicting $28 \%$ of the variance in 
constructive learning experiences, $R=.53, F(8)=8.98, p<.001$. Collinearity diagnostics were high with Condition Index, $C I=39.34$, however no variable had more than one value $>.50$. Tolerances range from .716 to .963 .

Three individual variables were significant predictors of constructive learning experiences according to faculty members: use of modeling and facilitation, faculty inclusion, and student inclusion, (See Table 17). The use of rules in the classroom was not significant in the model but had a significant bivariate correlation with constructive learning experiences, $r=.23, p<.01$. The discrepancy between zeroorder and partial correlations for rules ( $r=.25$ and $r=.10$ respectively), along with a relatively low tolerance (.792) suggests that rules as a variable shares considerable variance with other variables, reducing its individual effects.

Table 17

Standard Multiple Regression Predicting Constructive Classroom Discussion of Spirituality

\begin{tabular}{lccc}
\hline Variable & $B$ & $S E B$ & $\beta$ \\
\hline Use of classroom rules & .07 & .05 & .09 \\
Use of modeling and facilitation & .23 & .06 & $.24 * *$ \\
Faculty inclusion & .05 & .02 & $.24 * *$ \\
Student inclusion & .08 & .03 & $.23 * *$ \\
Age & .01 & .01 & .11 \\
Female gender & -.06 & .16 & -.02 \\
Full-time & .02 & .16 & .01 \\
Ethnicity & .15 & .18 & .06 \\
\hline$* p<.05, * * p<.01$ & & &
\end{tabular}




\section{Question 7}

What factors predict inclusion of spirituality by faculty with little personal experience with spirituality?

Dependent variable: faculty inclusion of spirituality

Independent variables:

- Content in own education

- School offers a course in spirituality

- Student inclusion of spirituality

- Friends who value spirituality

Educational preparation, school offers a course, student inclusion, and friends value spirituality were entered into a standard multiple regression as predictors for faculty inclusion of spirituality, analyzing a subset of faculty with less personal experience with spirituality (scoring at or below the mean on faculty personal experience) to determine the influence of personal experience on faculty inclusion. Twelve cases had missing values, resulting in a total of 118 faculty members with a low degree of personal experience with spirituality, comprising $53 \%$ of the total sample.

The model as a whole was significant, predicting $40 \%$ of the variance in faculty inclusion of spirituality, $R=.63, F(8)=9.04, p<.001$. Tolerances range from .865 to .962 . Three individual variables were significant predictors of faculty inclusion of spirituality among those with low personal experience: student inclusion, full time status, and female gender, (See Table 18); student inclusion alone accounted for $20 \%$ of the variance for this subset of faculty members. 
Table 18

Standard Multiple Regression Predicting Faculty Inclusion for Faculty with Less Personal Experience with Spirituality

\begin{tabular}{lccc}
\hline Variable & $B$ & $S E B$ & $\beta$ \\
Content in own education & -.24 & .31 & -.06 \\
School offers course & -1.88 & 1.00 & -.14 \\
Student inclusion & .73 & .12 & $.48 * *$ \\
Spiritual friends & -.03 & .23 & -.01 \\
Age & -.03 & .04 & -.05 \\
Female gender & 2.11 & .93 & $.18 *$ \\
Full-time & 2.51 & .89 & $.22 * *$ \\
Ethnicity & -.53 & 1.04 & -.04 \\
\hline
\end{tabular}

$* p<.05, * * p<.01$

\section{Question 8}

What overall model of relationships explains components necessary for constructive classroom discussion of spirituality?

Question 8 introduces an exploratory component; an attempt to construct an overall model to explain constructive classroom discussion of spirituality. Alternative models were constructed based on theorized relationships and informed by the above analyses. Bivariate correlations and regression results suggest basic relationships among variables, but raise questions about the inter-relationship of student inclusion and faculty inclusion of spirituality. With student inclusion predicted by faculty inclusion, faculty inclusion predicted by student inclusion, and both predicting constructive discussion of spirituality, it is not clear if one of these variables might play a more important role, or if they are equally important.

Three path models were constructed, using AMOS and SPSS software, which differ only in terms of directional paths between student inclusion and faculty inclusion. Model A posits that faculty inclusion leads to student inclusion, model B posits that student inclusion leads to faculty inclusion, and model $\mathrm{C}$ is bi-directional, 
reflecting results that suggest that each predicts the other (see Figures 4-6 below).

Comparison of the three models may help us understand the underlying dynamics between faculty and student inclusion of spirituality. Given the exploratory nature of this path analysis, conclusions from this analysis must be considered preliminary.

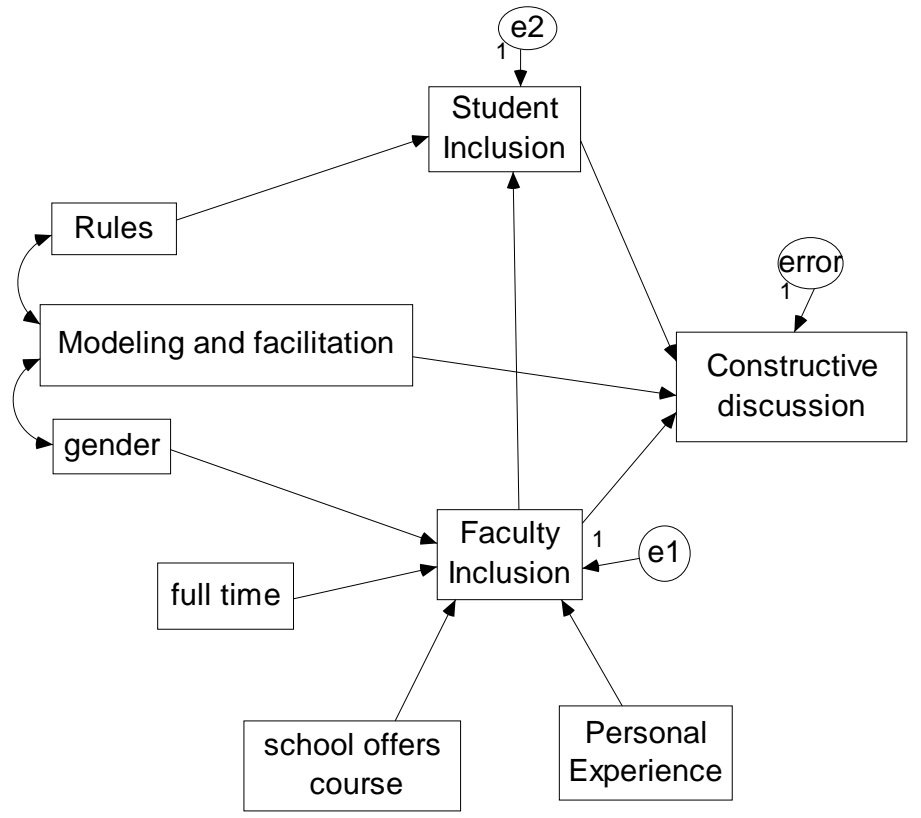

Figure 1. Path model A. 


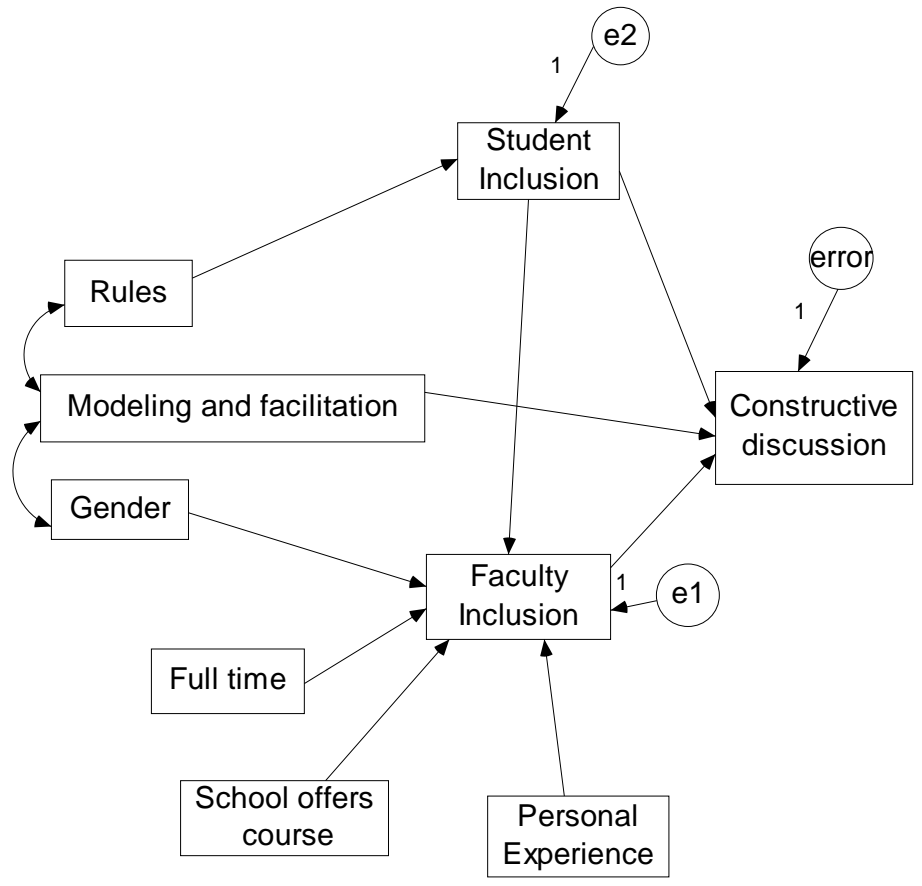

Figure 2. Path model B.

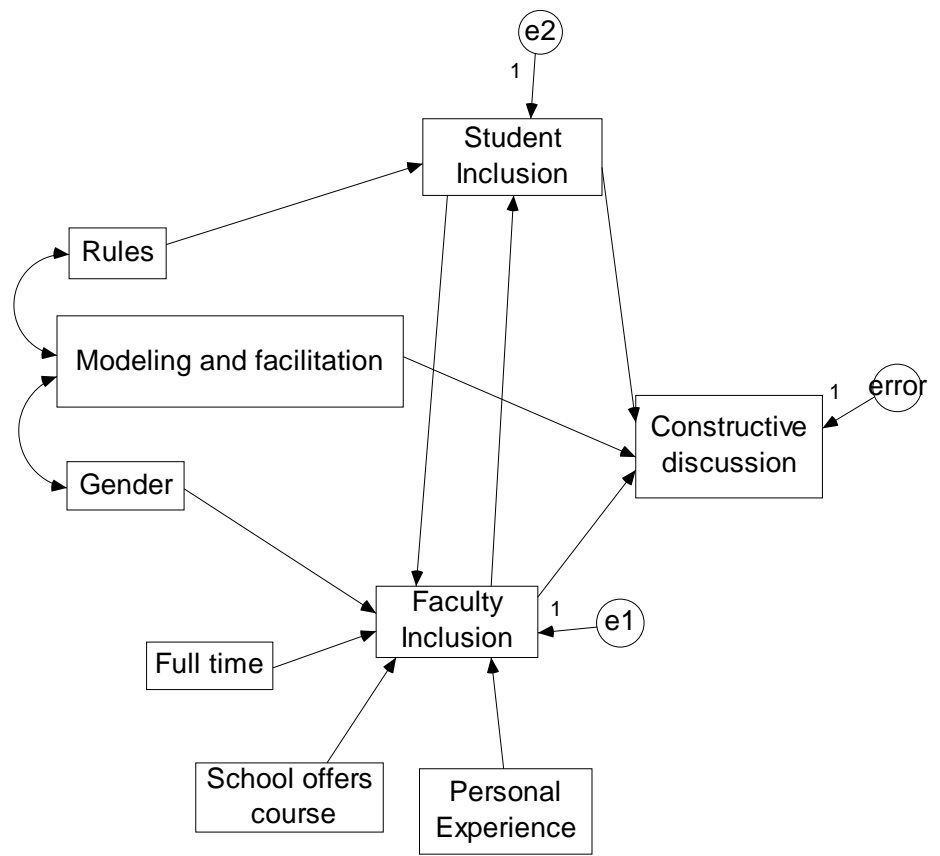

Figure 3. Path model C. 
Possible mediating relationships between variables in the models were tested using AMOS and SPSS; two mediators were found. Faculty members' personal experience of spirituality influenced student inclusion through the mediator of faculty inclusion; and faculty members' gender influenced student inclusion through the mediator of faculty inclusion.

Table 19 below contains a comparison of fit measures for each of the three models, obtained using AMOS and SPSS software. The path analysis was attempted using the full dataset $(N=222)$; however, missing data prohibited AMOS from fitting the data to saturated models, which means that fit indices were not available for model comparison. Therefore, the three models were run with the smaller dataset without any missing values $(N=192)$.

All three models fit better than the baseline, which posits a total lack of relationships between variables. The chi-square statistics, which measure the discrepancy of predicted models and the data, are non-significant for all models, indicating that they fit the data well. There is no significant difference between the three chi-squares. Fit indices for the models are very similar, as might be expected, making it difficult to determine which model best explains the relationships between variables.

Four fit indices were chosen to assist in model comparison. Three of these measures are recommended by Russell (2002): the Incremental Fit Index (IFI) and Comparative Fit Index (CFI), which are comparisons to a model with no relationships among variables, and the Root Mean Square Error of Approximation (RMSEA). 
Russell recommends an IFI and CFI of .95 or greater, and an RMSEA of .06 or lower. The Akaike Information Criterion (AIC), is frequently used for model comparison, with lower scores indicating better fit. According to the fit indices, Model A fits the data better relative to the other models (see Table 19), which would indicate that faculty inclusion leads to student inclusion.

Table 19

Path Model Comparisons: Goodness of Fit Measures

\begin{tabular}{lcccc}
\hline & Baseline & & & \\
Measure & Model & Model A & Model B & Model C \\
\hline $\mathrm{X}^{2}$ & 190.955 & 28.08 & 30.08 & 27.66 \\
$\mathrm{R}^{2}$ Constructive discussion & & .25 & .25 & .25 \\
$\mathrm{IFI}$ & .000 & .981 & .969 & .978 \\
CFI & .000 & .980 & .967 & .976 \\
RMSEA & .150 & .025 & .033 & .028 \\
AIC & 208.955 & 68.082 & 70.077 & 69.658 \\
\hline
\end{tabular}

Confirming the choice of model A, the path from student inclusion to faculty inclusion in Model C (where both paths are included) is not significant. The path from personal experience to faculty inclusion in Model B is also not significant, a likely reflection of the mediation between personal experience and student inclusion through faculty inclusion.

Path coefficients for the final path model are displayed in Figure 7. 


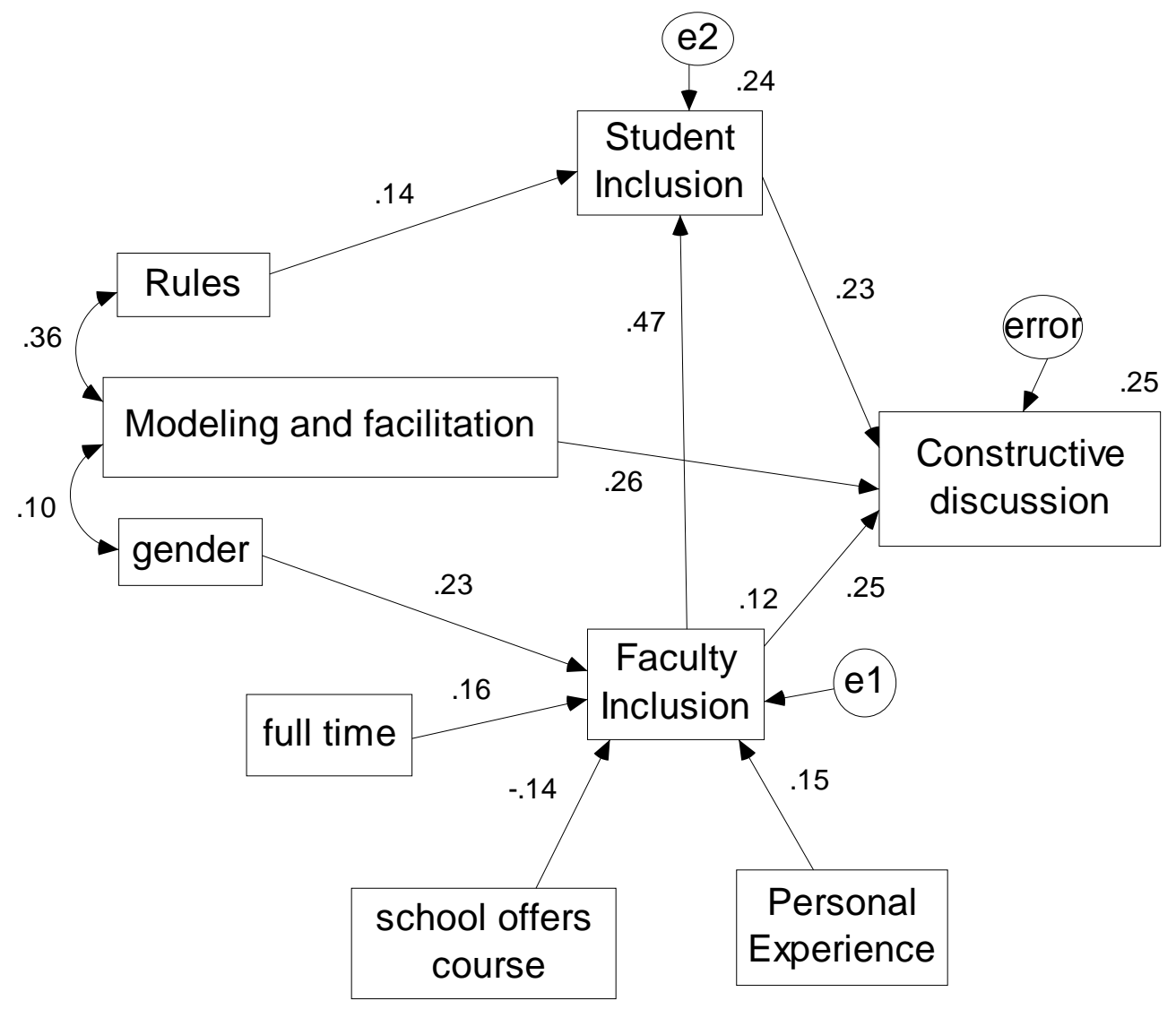

Figure 4. Final path model with standardized coefficients and explained variance for outcome variables

Note: All coefficients are significant. Amount of variance explained is located above outcome variables. 


\section{Discussion}

Relevance of spirituality to social work. Seventy percent of faculty members in the current sample agreed or strongly agreed that spirituality is an aspect of being human, and seventy-seven percent agree that knowledge of spirituality is important for social work. This confirms earlier findings that a majority of social work educators view spirituality and religion as relevant to social work practice and social work education (Dudley \& Helfgott, 1990; Sheridan et al., 1994). While faculty members with a higher degree of personal experience with spirituality were more likely to view spirituality as a fundamental aspect of being human, the study found that having friends or family members who value spirituality also contributes to a recognition that spirituality is an important part of human experience. This finding is consistent with Hodges' (2003) assertion that a faculty member's exposure to a spiritual perspective through contact with people who value spirituality can foster the development of respect for spirituality.

Culture and ethnicity also influence faculty member's views about the importance of spirituality. As noted earlier, shared cultural heritage often involves participation in spiritual or religious practices. In spite of the small representation of minority populations in this sample, racial or ethnic identity predicted an appreciation of spirituality as a fundamental aspect of being human. Older faculty members were also more likely to see spirituality as an aspect of human experience, possibly reflecting an increased interest in finding meaning and purpose as they face the transitions and health issues that accompany growing older (Ai, 2002). 
Vote for a course. A majority of faculty members in the present study supported offering an elective course in spirituality. With a response rate of $52 \%$, similar to that obtained by Sheridan et al. (57\%) and Dudley and Helfgott (56\%), it is reasonable to compare results of the current study with those of the two previous studies. Over the 17 year time-span represented by the Dudley and Helfgott (1990), Sheridan et al. (1994), and present study, successively more faculty members voted for a separate course in spirituality and social work. Sheridan's sample was the most likely to vote for a required course, possibly reflecting demographic differences in her sampling frame, which included sectarian schools and was largely based in the Southeastern United States. Furman et al. (Furman, Perry W. Benson, \& Canda, 2004) note that while previous Gallup surveys of religion found that people living in Southern states tend to be more religious, their own national study of social workers did not find major regional differences. Furman et al. speculated that the inclusion of religion and spirituality in versions of CSWE regulations published in 1994 and 2003 may account for a reduced geographic differentiation among social workers in 2004.

Schools are increasingly offering elective courses in spirituality. A consistent increase in number of schools offering a course has been documented; from $9 \%$ of Sheridan's (1994) sample reporting that their school offered a course in spirituality, to $44.6 \%$ of schools surveyed by Kilpatrick and Puchalski (1999), to the present study where 17 out of 22 schools in the sample (77\%) now offer a course in spirituality.

Faculty inclusion of spirituality. Two-thirds of faculty members in the sample reported that they incorporate the topic of spirituality into courses they teach to some extent. The strongest predictor of faculty inclusion was the faculty member's 
perception of student inclusion of spirituality in class discussion, in consultation with the faculty member, or as content in written assignments. The experience of constructive discussions was also a strong predictor of faculty inclusion. When faculty members perceive that students are interested in the topic of spirituality, and that discussions of spirituality are positive and productive, they appear to be more likely to discuss the topic themselves. The existence of a course in the curriculum dealing specifically with spirituality or religion in relation to social work practice was another significant predictor of faculty inclusion. The coefficient was negative, indicating that the absence of a course in spirituality or religion predicted faculty inclusion. This is an interesting finding which runs counter to the notion that school sanction of the importance of spirituality by including a specific course on the relationship of spirituality to social work practice would create an atmosphere where faculty members would be more likely to include the topic. The results, on the other hand, suggest that faculty members who teach in schools that do not include a separate course in spirituality are more likely to include the topic in their courses.

Faculty members who were female were more likely to report that they included spirituality in course content than male faculty members. This difference is difficult to explain. Although the literature suggests that women in general are more inclined to be spiritual or religious than men (Thompson, 1991; Woodhead, 2001), further examination of data from the current sample shows that male and female faculty members reported the same level of engagement in private spiritual practices and involvement with spiritual or religious groups. In other words, even though both genders report the same level of personal involvement with spirituality, female 
participants reported more inclusion of spirituality in the classroom. Further investigation is necessary to understand whether this gender difference in reported faculty inclusion is an artifact of this sample, or reflects the involvement of yet unidentified factor.

Full-time faculty members were more likely to report inclusion of spirituality in their courses than part-time faculty members. Part-time faculty members were, on the other hand, more likely to vote for a required course in spirituality, as opposed to an elective course. Reasons for these differences are not clear, but could reflect discomfort or uncertainty by part-time faculty members about how to incorporate spirituality in courses. In distinct ways, both full and part-time faculty members' responses reflect an appreciation of the importance of including spirituality in social work education.

Student inclusion of spirituality. From faculty members' perspective, when they introduce the topic of spirituality and the resulting discussion is constructive, students are more likely to bring up the topic in class. Faculty inclusion was the strongest predictor of student inclusion. Surprisingly, faculty members' perception of conflict or heated discussion also significantly predicted faculty perception of student inclusion, and was actually a slightly stronger predictor of student inclusion than constructive discussions. This suggests that discussion of any kind on the topic of spirituality may encourage student input, counter to the idea that conflict stifles further discussion on a topic.

The use of classroom rules was also a significant predictor of student inclusion. The significance of classroom rules to student inclusion confirms Rendons' (2000) 
assertion that classroom rules promoting respect for different points of view creates a sense of safety, necessary for discussing sensitive topics like spirituality.

Constructive classroom discussion. Achieving the goal of respect for differing views in the classroom, including spirituality, depends to some degree upon student and faculty members' experience of constructive classroom discussion regarding the topic. The three significant predictors of constructive discussion were almost equal in predictive power. The use of modeling and facilitation of respect was only a slightly stronger predictor than faculty inclusion and student inclusion. All three appear to be important elements of constructive classroom discussions of spirituality.

Impact of Low Personal Experience on Faculty Inclusion. The analysis of faculty inclusion which focused on faculty members with lower amounts of personal experience with spirituality had similar results to that of the full sample, with a couple of exceptions. For these faculty members, student inclusion was a notably strong predictor, accounting for $20 \%$ of the variance in faculty inclusion. It appears that the experience of student inclusion is a stimulus for faculty inclusion of spirituality for some faculty members who have less personal experience with spirituality. Given the high rate of inclusion of spirituality for the sample as a whole, it is clear that many faculty members who are not particularly interested in spirituality are nonetheless responsive to student interest in the topic.

The other difference in inclusion of spirituality for faculty members with lower amounts of personal experience with spirituality was that the existence of a course on spirituality was not significant. These faculty members were less likely to bring up the topic, whether or not the school offered a course in spirituality and social work. 
Content in own education. It was hypothesized that content on spirituality in one's own social work education would influence a faculty members' inclusion of spirituality in their courses. However, few faculty members reported receiving content on spirituality in their own social work education, confirming results found by other researchers (Ai, 2002; Ai et al., 2004; Cnaan et al., 1999; Sheridan et al., 1992; Sheridan \& Hemert, 1999). Younger faculty members reported more content than older faculty members, suggesting an increase in content regarding spirituality in social work education in more recent years. In fact, results of this study show that a majority of faculty members in the sample report that they incorporate spirituality in their courses, so current students are more likely to be exposed to the topic than their professors were. Although one's own education did not impact inclusion of spirituality in the current study, future studies are likely to show different results as social work education increasingly incorporates the topic of spirituality.

Personal experience with spirituality. As noted above, faculty members' personal experience with spirituality significantly predicted faculty member's views regarding spirituality as an aspect of being human and the importance of spirituality for social work practice. Faculty members with less personal experience are less likely to have friends or family members who value spirituality; close to $40 \%$ of this sub-set knew fewer than six people who value spirituality. The significant positive correlation between personal experience and faculty inclusion suggests that faculty members with little personal experience are less likely to include spirituality; although many do. Thirty percent of faculty members with a low degree of personal experience with spirituality rated themselves at the mean or above on faculty inclusion. This indicates 
that many faculty members who do not personally consider themselves spiritual demonstrate respect for people who do, reporting that they incorporate the topic of spirituality into their courses.

Although personal experience did not directly predict faculty inclusion of spirituality, it did indirectly affect student inclusion of spirituality through the mediator of faculty inclusion. Personal experience with spirituality affects faculty members' perceptions and values, shaping their attitudes and ways of relating to students, including use of rules, modeling, and facilitation, in ways that show respect for spirituality as a part of human experience. These attitudes and behaviors, in turn, affect students' comfort with and likelihood of bringing up the topic of spirituality.

Although the majority of faculty members identified themselves with a spiritual tradition, they reported widely differing relationships with spirituality. Fortytwo percent of faculty members reported never or rarely engaging in spiritual practices such as meditation, prayer, inspirational reading or spiritual journaling, while an equal proportion (43\%) reported that they participate in spiritual practices on a regular basis (nearly every week to several times daily). Similarly, over a third of the sample reported regular participation and some involvement with a spiritual or religious group (34.8\%), and a comparable percent reported no identification, participation, or involvement (32.4\%). This suggests very different conceptions of and experiences with spirituality across the sample. We might expect that faculty members with such divergent personal experiences with spirituality would approach the topic of spirituality very differently from one another. 
Confirming analyses by Hodge (2002), beliefs of social work faculty members in this sample differ in important ways from those held by members of the general public. The comparison of the faculty sample with the general population (Pew Forum on Religion \& Public Life (2007) showed that faculty members were more likely to be Agnostic, Atheist, or affiliated with non-traditional spiritualities, and less likely to be Evangelical Protestant or Catholic than the general public. These differences in perspective may make it more difficult for faculty members to relate to or understand the perspectives of students or client groups from more traditional spiritual backgrounds.

Putting it All Together: the Path Analysis. Consistent with the above analyses, the path analysis indicates that use of modeling and facilitation to promote respect for differences, faculty inclusion of spirituality, and student inclusion of spirituality all contribute to constructive discussions of spirituality. The strongest path in the model represents the influence faculty inclusion of spirituality has on student inclusion. Two indirect effects were identified; the influence of faculty members' personal experience with spirituality on student inclusion through faculty inclusion; and the influence that female faculty members have on student inclusion through the faculty members' inclusion of spirituality.

Rules for respectful discourse had a significant influence on student participation. Modeling respect and facilitating classroom discussion, on the other hand, had a significant influence on constructive classroom discussion. These results suggest that the use of classroom rules serves a separate function in classroom dynamics than modeling and facilitation of respectful discussion. Rules may set a tone 
and possibly an expectation of safety for students, encouraging participation in the discussion; while modeling and facilitation are active components of classroom discussion, creating a safety in-the-moment which may contribute to a constructive outcome.

\section{Limitations}

Many measures used in the study do not have previously established reliability and validity data from prior studies. Attempts were made to improve validity by asking five social work educators to examine the survey and provide feedback regarding clarity of the items, which lead to refinement of several measures. The untested nature of these items, however, is a limitation.

This study measured faculty perceptions of inclusion of spirituality in their classrooms. Items measuring student inclusion of spirituality in classroom discussions in particular are more accurately understood as measures of faculty perceptions of student inclusion of spirituality. Student perceptions of faculty inclusion, the nature of that inclusion, and the outcomes of discussion, however, may be quite different.

Further refinement of several variables in this study would have made these variables more useful. Variables measuring constructive discussion and conflict or heated discussion need to be further defined to ensure a uniform understanding of these constructs. Subjective measures of satisfaction with their own education, and faculty members' sense of being prepared to discuss spirituality in the classroom were particularly difficult to interpret. These items appeared to be measuring qualities other than the intended constructs, and were omitted from the analyses. 
Due to the homogeneity of views and behaviors among faculty members, many variables in this study had skewed distributions, which can possibly inflate or deflate estimations. To some degree this is an unavoidable artifact which reflects common training and shared values among study participants.

This study surveyed faculty members from schools rated as the US News and World Reports' top social work programs; chosen through peer review to represent model social work programs. These are more likely to be large urban research universities which attract and retain well-respected professors and whose reputations are established through publication in research journals and conference presentations. Smaller colleges and universities were therefore not represented in this sample, along with sectarian or religiously affiliated schools of social work. The sample was selected from faculty members at the top rated schools who teach primarily social work practice, HBSE, and diversity courses, not those who teach courses primarily related to social work policy, administration, or research. For a number of reasons, therefore, these results cannot be generalized to all social work educators or social work programs.

\section{Theoretical Implications}

Application of critical theory to social work education posits that constructive learning experiences result when students are encouraged to share their own perspectives, experiences, and views, allowing for discussion of diverse points of view. Modeling of respect and facilitation of classroom discussion are highlighted as ways to encourage constructive discussions. Results of this study suggest that faculty believe the use of classroom rules for respectful discussion may be helpful in creating 
an environment where students are comfortable discussing diverse viewpoints and sharing their personal perspectives.

In addition, it is not enough to merely allow opinions to emerge on their own, but faculty introduction of the topic of spirituality is important and may be necessary in order to elicit discussion of the topic of spirituality. The most constructive discussions are likely to result when faculty members bring up the topic, model respect for spirituality and when they facilitate discussions to promote respect for diverse perspectives.

Application to Policy and Practice

This study confirms a continuing increase in awareness and inclusion of spirituality in social work education. It is difficult to know whether the recent inclusion of religion and spirituality in the CSWE Educational Policy and Accreditation Standards (Council on Social Work Education, 2001) prompted this increased awareness, or was the result of an already growing interest in these topics. The fact that seventy-five percent of faculty surveyed report that they now incorporate spirituality into their courses is quite possibly a result of the policy change.

Social work education in general may benefit from an increased awareness of the relevance of spirituality, particularly in the area of cultural competence. The relatively low percentage of people of color among survey respondents highlights the importance of minority faculty recruitment and retention. Acknowledgement of the importance of spirituality for many cultural groups, and sensitivity to the role that spirituality may play in the lives of faculty members may create a more welcome and affirming environment for diverse faculty members and students. 
As noted earlier, several important concerns have been raised about the inclusion of spirituality in social work education. Spirituality is a very complex and sensitive topic and must be approached with care. Survey comments from faculty members echo the concern that if not handled correctly, discussion of the topic of spirituality could have a negative as well as positive impact on students.

Two of the major concerns mentioned earlier may provide a framework for thinking about ways that spirituality can be handled in ways that enhance social work education. One concern is that spirituality encompasses such an expansive topic that it is impossible to expect social work faculty members to routinely incorporate it in their courses. In this regard, spirituality is much like the topic of ethnic diversity, with an unlimited number of possible forms or manifestations. If spirituality is approached as a diversity issue, with a client-centered focus, faculty members can foster curiosity about the possible role spirituality plays in clients' lives. In the same way that students learn about the experiences of clients who are culturally different from themselves, students can learn about a client's unique worldview, including spirituality, by listening with respectful curiosity. Social work values of client selfdetermination, honoring cultural diversity, focusing on client strengths, and strengthening social support networks provide a solid foundation for incorporating the topic of spirituality in social work education.

A second concern is that spirituality is an intensely personal issue that could lead to proselytizing and misuse of power. Social work values provide a way to guard against the attempts of some to change or influence the beliefs of others. Social work educators already encourage students to become aware of their own values and 
underlying motivations in order to move beyond personal perspectives and relate to clients in an open and non-prejudicial manner. In order to accomplish this, social work students are asked to engage in self-reflection to increase awareness of underlying values, beliefs, and motivation. If spirituality is included as a topic for awareness and self-reflection, students will be more likely to pay careful attention to not imposing their own personal values or beliefs on others. Social work students who have the opportunity for self-reflection and awareness, and are able to explore the topic of spirituality as it applies to social work practice, will be more sensitive to the role that spirituality potentially plays in the lives of clients.

Although, as noted above, inclusion of spirituality in social work education is feasible using tools already available to social work educators, there is reason to be cautious as well. Almost one third of faculty members surveyed reported no identification, participation, or involvement with spirituality or religion. This indicates that faculty members who do not personally value spirituality are leading class discussions on the topic. Many of these faculty members have had past negative experiences with religion, which likely affects the way they approach the topic of spirituality.

Several studies have documented that Christian social workers (Ressler \& Hodge, 2000) as well as Christian social work graduate students (Hodge, 2007) perceive discrimination against them due to their religious affiliation. Anecdotal evidence obtained both locally and from a national network of Christian social work students from both Evangelical and Mainline Protestant traditions suggests that, while faculty members respect spirituality in general, students are frequently confronted with 
negative stereotypes of Christianity in the classroom. This highlights the need for careful consideration of ways to promote constructive discussion and respect for views which differ from or conflict with one's own.

Two resources in particular may be helpful to social work educators who wish to promote a type of respect which surmounts seemingly incompatible worldview differences. One is a short article by Eyal Press titled In God's Country, published in The Nation (Press, 2006), which provides secular readers with a balanced perspective on the current exercise of religion in America. Press presents a critical critique of both religious and secular positions, advocating for increased understanding and tolerance on the part of both. The second resource was discussed earlier, a book by James Davison Hunter (1991), Culture Wars: The Struggle to Define America. Hunter likewise presents opposing views fairly, and concludes by suggesting that constructive discussion results from recognizing and respecting the non-negotiable core beliefs of others and humbly recognizing legitimate critiques of our own.

\section{Areas for Future Research}

This study is the first to attempt to quantify and explain the inclusion of spirituality in social work education and factors involved in constructive classroom discussion of spirituality. Future studies incorporating outcome variables from this study would be helpful to provide validation of these variables. Identification and confirmation of factors associated with faculty and student inclusion of spirituality, as well as constructive discussion and conflictual discussion is needed to further refine these constructs. 
As a study of faculty members, results of the current study are based solely on faculty members' reports and their perceptions of inclusion of spirituality in the classroom. Further research which examines students' perceptions of their own level of inclusion of spirituality in class and the degree and quality of faculty members' inclusion of spirituality would provide a valuable counterpoint to the current study.

Students could also be asked to identify topics they find difficult to discuss in class, and topics that provoke heated debate. Feedback regarding student experiences of being misrepresented or discriminated against either in course content or class discussions, including experiences of spiritual or religious discrimination, would be valuable. Studies similar to this one could be done on other topics in social work identified as potentially divisive to provide information about the generalizability of these results to other areas of discussion in the classroom. Ideally, a study could be done which elicited responses from both faculty members and students involved in a particular class to provide a more complete picture of the nature and extent of classroom content regarding spirituality.

The outcome variables constructive discussion and conflictual discussion need to be more precisely defined, preferably across multiple dimensions to increase validity. Research asking both faculty members and students how they know when a class discussion has been constructive, how they would define a constructive learning experience and what elements contribute to constructive classroom discussions would better refine this construct. Similar questions could be asked about conflictual or heated discussion in the classroom. The relationship between conflictual discussion and constructive learning experiences could be explored in more depth. Information 
regarding conditions contributing to positive resolution of conflict in the classroom, and those which leave conflict unresolved and results in negative outcomes is necessary to clarify this relationship.

In the current study, use of the classroom management techniques of modeling and facilitation were significant predictors of constructive classroom discussion, while the use of rules was a significant predictor of student inclusion. These findings suggest that the use of rules for respectful discussion impacts different aspects of classroom dynamics than do modeling and facilitation of respectful discussion. Further refinement of each of these variables in future studies would provide increased understanding of the role each of these techniques plays in classroom dynamics.

This study, while asking faculty members if they incorporate the topic of spirituality into their courses, does not gather information about the nature and content of the material regarding spirituality. As noted earlier, faculty members have a wide range of different personal experiences with spirituality, and would likely approach the topic of spirituality very differently depending on the nature of their own knowledge or personal experience with spirituality. A valuable next step would be to study the content of material introduced in classes, particularly what aspects of spirituality are discussed, as well as the context and manner in which it is discussed. Examination of course syllabi, textbooks, and assigned readings could provide information about the nature of the content introduced, and interviews or focus groups with students and faculty members could provide information about the context and the nature of discussions involving spirituality, as well as classroom dynamics that accompany these discussions. Observational research involving videotaping of 
classroom sessions is another technique which could help us understand subtle aspects of classroom dynamics.

In addition to identifying textbooks and articles currently used in social work classrooms, additional materials need to be identified which could help social work educators who want to improve their ability to address spirituality in their courses and social work practitioners who are interested in improving their ability to work constructively with people who value spirituality. The number of resources on the topic of spirituality in social work practice and social work education has increased dramatically in recent years, and a published review of available articles, books, and seminars would help social workers access these resources.

\section{Conclusion}

Results of this study confirm results of previous studies; a majority of faculty members in this sample reported that they view the topic of spirituality as relevant to social work practice as an aspect of human development. Faculty members' personal beliefs and experience with spirituality influenced their views on the relevance of spirituality in human development and for social work practice, and indirectly influenced student inclusion of spirituality. Faculty members with little personal experience with spirituality but who had friends or family members who value spirituality were also more likely to view spirituality as relevant to human experience and to social work practice. This suggests that personal experience with spirituality is not necessarily a prerequisite for promotion of respect for diversity that includes spirituality. 
While faculty members support offering a separate course in spirituality and social work, they often include the topic of spirituality in the content of regular courses in the social work curriculum. Faculty inclusion of spirituality was found to be a key element of classroom discussions leading to constructive discussions of spirituality. When faculty members introduce the topic, students are more likely to discuss spirituality. Conversely, when faculty members do not introduce the topic of spirituality, it is less likely to be brought up. The use of classroom rules to promote respect for differences is related to increased student discussion of spirituality, and faculty members' use of modeling and facilitation promotes constructive discussions on the topic.

Spirituality is just one of many aspects of diversity in our multicultural society which challenges social workers to develop respect for differences. There is an ongoing need for study and consideration of ways to promote respect for views and beliefs that differ from one's own, both for the social work practitioner who deals with clients, and the social work educator challenged to foster respect for difference in the classroom. 


\section{References}

Ai, A. L. (2002). Integrating spirituality into professional education: A challenging but feasible task. Journal of Teaching in Social Work, 22(1/2), 103-128.

Ai, A. L., Moultine, K., Picciano, J. F., Nagda, B., \& Thurman, L. H. (2004).

Integrating spirituality into the social work curriculum: A student-initiated program evaluation. Journal of Teaching in Social Work, 24(1/2), 105-127.

Aiken, L. A. (1996). Rating scales and checklists: Evaluating behavior, personality, and attitudes. New York, NY: Wiley.

Allport, G. W. (1950). The individual and his religion: A psychological interpretation. New York: Macmillan.

Applebaum, B. (2003). Social justice, democratic education and the silencing of words that wound. Journal of Moral Education, 32(2), 151-162.

Barker, R. L. (2003). The social work dictionary (5th ed.). Washington, DC: NASW Press.

Baylor University. (2006). American piety in the 21st Century: New insights to the depth and complexity of religion in the US [Electronic]. Baylor Institute for Studies of Religion. Available: http://isreligion.org/research/surveysofreligion/americanpiety [2007, 03/14/07].

Brazelton, T. B., \& Greenspan, S. I. (2000). The irreducible needs of children. Cambridge: Da Capo Press.

Bullis, R. K. (1996). Spirituality in social work practice. Washington DC: Taylor and Francis.

Canda, E. R., \& Furman, L. D. (1999). Spiritual diversity in social work practice: The heart of helping. New York: Free Press.

Clark, J. (1994a). Response to Katherine Amato-von Hemert. Journal of Social Work Education, 30(1), 11-12.

Clark, J. (1994b). Should social work education address religious issues? No! Journal of Social Work Education, 30(1), 12-16.

Cnaan, R. A., Wineburg, R. J., \& Boddie, S. C. (1999). The newer deal: Social work and religion in partnership. New York: Columbia University Press. 
Council on Social Work Education. (2001). Educational Policy and Accreditation Standards .

Crocco, M. S. (2004). Dealing with difference in the social studies: A historical perspective. International Journal of Social Education, 18(2), 106-26.

Dalton, B. (2005). Teaching cultural assessment. Journal of Journal of Teaching in Social Work, 25(3/4), 45-61.

Dillman, D. A. (2000). Mail and internet surveys: The Tailored Design Method. New York, John Wiley \& Sons, Inc.

Dillman, D. A. (2007). Mail and internet surveys: The Tailored Design Method 2007 update with new internet, visual, and mixed-mode guide. Hoboken, New Jersey, John Wiley and Sons, Inc.

DuBois, B., \& Miley, K. K. (2005). Social work: An empowering profession (5th ed.). New York: Pearson Education, Inc.

Dudley, J. R., \& Helfgott, C. (1990). Exploring a place for spirituality in the social work curriculum. Journal of Social Work Education, 26(3).

Ellison, C. G., \& Levin, J. S. (1998). The religion-health connection: Evidence, theory, and future directions. Health Education \& Behavior, 25(6), 700-720.

Ellor, J. W., Netting, F. E., \& Thibault, J. M. (1999). Understanding religious and spiritual aspects of human service practice. Columbia, S.C.: University of South Carolina Press.

Furman, L. D., Perry W. Benson, \& Canda, E. R. (2004). Religion, spirituality, and geographic region in the USA: An examination of regional similarities and differences among social workers in direct practice. Social Work \& Christianity, 31(3), 267-294.

Galanter, M., \& Buckley, P. (1978). Evangelical religion and meditation:

Psychotherapeutic effects. Journal of Nervous and Mental Disease, 166, 685-91.

Garmon, M. A. (2005). Six key factors for changing preservice teachers' attitudes/beliefs about diversity. Educational Studies: Journal of the American Educational Studies Association, 38(3), 275-86.

Gartner, J. (1996). Religious commitment, mental health, and prosocial behavior: A review of the empirical literature. In E. P. Shafranske (Ed.), Religion and the Clinical Practice of Psychology (pp. 187-214). Washington, D.C.: American Psychological Association. 
Gibbons, J., \& Gray, M. (2004). Critical thinking as integral to social work practice. Journal of Teaching in Social Work, 24(1/2), 19-38.

Haught, N. (2001, 1/31/01). Bush's faith-based plan leaves agencies 'cautiously optinistic'. The Oregonian.

Hodge, D. R. (2002a). Does social work oppress evangelical christians? A "new class" analysis of society and social work. Social Work, 47(4), 401-414.

Hodge, D. R. (2002b). Equally devout, but do they speak the same language?

Comparing the religious beliefs and practices of social workers and the general public. Families in Society: The Journal of Contemporary Social Services, 83(5/6), 573-584.

Hodge, D. R. (2003a). The challenge of spiritual diversity: Can social work facilitate an inclusive environment? Families in Society: The Journal of Contemporary Social Services, 84(3), 348-358.

Hodge, D. R. (2003b). Differences in worldviews between social workers and people of faith. Families in Society: The Journal of Contemporary Social Services, 84(2), 285-294.

Hodge, D. R. (2007). Religious discrimination and ethical compliance: Exploring perceptions among a professionally affiliated sample of graduate students. Journal of Religion and Spirituality in Social Work, 26(2), 91-113.

Hosmer, D. W., \& Lemeshow, L. (2000). Applied logistic regression (2nd ed.). New York: Wiley.

Hunter, J. D. (1991). Culture wars: The struggle to define America. New York: Basic Books.

Johnson, P. E. (1993). Darwin on trial. Downer's Grove, IL: InterVarsity Press.

Joseph, M. V. (1987). The religious and spiritual aspects of clinical practice: a neglected dimension of social work. Social Thought, 13(1), 12-23.

Keith-Lucas, A. (1989). The poor you have with you always. St. Davids, PA: North American Association of Christians in Social Work.

Kilpatrick, S. D., \& Puchalski, C. (1999, November 5-6). Spirituality and religion in the classroom: A survey of academic departments. Paper presented at the Society of Southeastern Social Psychologists Conference, Richmond, VA.

Kirkman, T. W. (1996). Statistics to use. Available:

http://www.physics.csbsju.edu/stats/ [2009, February 9]. 
Knowles, M. (1978). The adult learner: A neglected species. Houston: Gulf Publishing Company.

Koenig, H. G. (1999). The healing power of faith: Science explores medicine's last great frontier. New York: Simon \& Schuster.

Littlejohn, S. W. (1992). Theories of human communication (4th ed.). Belmont, CA: Wadsworth Publishing Co.

Marty, M. E. (1980). Social service: Godly and godless. Social Service Review, 54(4), 463-81.

Mayo Clinic. (2007, 10/ 26/ 2007). Complementary and Alternative Medicine: What is it?, [Electronic]. Mayo Foundation for Medical Education and Research. Available: http://www.mayoclinic.com/health/alternative-medicine/PN00001 [2009, April 23].

Miller, D. W. (2001). Programs in social work embrace teaching of spirituality. Chronicle of Higher Education, 47(36).

Morse, R. J., \& Flanigan, S. (2007). America's Best Graduate Schools 2007: How We Do the Numbers, [Electronic]. US News and World Report [2007, 4/20/2007].

NASW. (2001). NASW cautious about Bush's faith-based initiative. (Press Release ). Washington: National Association of Social Workers, www.socialworkers.org/NASW/press_release/021401.htm.

NASW. (2002a, November 2002). Faith-based initiatives discussed. NASW News.

NASW. (2002b, January 2002). NASW priorities on faith-based human services initiatives, [email]. NASW Government Relations and Political Action. Available: email communication from Ann Bradford [2004, 5/5/04].

NASW, P. A. (2002c, December 16, 2002). NASW opposes Bush Faith-Based Executive Order: Discrimination should not be funded by taxpayers. National Association of Social Workers, Public Affairs [2003, 1/21/2003].

Newport, F. (2004). A look at Americans and religion today, [electronic]. The Gallup Poll Tuesday Briefing, March 23, 2004, pp111-114 [2004, June 2004].

Niebhur, R. (1932). The contribution of religion to social work. New York: Columbia University Press. 
NIH. (2005, 5/13/ 2009). NIH Newsletter: CAM at the NIH (Winter 2005), [Electronic]. National Institutes of Health. Available:

http://nccam.nih.gov/news/newsletter/2005_winter/prayer.htm [2009, April 23].

Olasky, M. (1992). The tragedy of American compassion. Wheaton: Crossway Books.

Oman, D., \& Thoresen, C. E. (2002). Does religion cause health?: Differing interpretations and diverse meanings. Journal of Health Psychology, 7(4), 365-380.

Palmer, P. J. (1990). Good Teaching. Change, 22(1), 10-16.

Palmer, P. J. (1998). Courage to teach: Exploring the inner landscape of a teacher's life. San Francisco: Jossey-Bass.

Palmer, P. J. (2003). Teaching with heart and soul: Reflections on spirituality in teacher education. Journal of Teacher Education, 54(5), 376-385.

Pargament, K. I., Ensing, D. S., Falgout, K., Olsen, H., Reilly, B., Van Haitsma, K., \& Warren, R. (1990). God help me (1): Religious coping efforts as predictors of the outcomes to significant negative life events. American Journal of Community Psychology, 18(6), 793-824.

Petrovich, A., \& Lowe, M. (2005). Developing cultural competence: Student and alumni perspectives. Journal of Teaching in Social Work, 25(3/4), 157-176.

Pew Forum on Religion \& Public Life. (2007, August 13, 2007). Religious Landscape Study. Pew Forum on Religion and Public Life [2009, February 12].

Press, E. (2006, November 20, 2006). In God's Country. The Nation, 31-38.

ReligionFacts. (2007, 2007). New Thought. ReligionFacts.com. Available: http://www.religionfacts.com/a-z-religion-index/new_thought.htm [2009, April 23].

Rendon, L. I. (2000). Academics of the heart. About Campus, July/August, 3-5.

Ressler, L. E., \& Hodge, D. R. (2000). Religious discrimination if social work: An international survey of Christian social workers. Christianity and Social Work, 27(1), 49-70.

Roof, W. C. (1993). A generation of seekers: The spiritual journeys of the Baby Boom generation. San Francisco: HarperSanFrancisco.

Rosenbaum, J. and C. W. Lidz (2007). Maximizing the results of internet surveys, Center for Mental Health Services Research, University of Massachusetts Medical School, Issue Brief, 4(2). 
Russell, D. W. (2002). In search of underlying dimensions: The use (and abuse) of factor analysis in Personality and Social Psychology Bulletin. Personality and Social Psychology Bulletin, 28(12), 1629-1646.

Saleebey, D., \& Scanlon, E. (2005). Is a critical pedagogy for the profession of social work possible? Journal of Teaching in Social Work, 25(3/4), 1-18.

Sheridan, M. J., Bullis, R. K., Adcock, C. R., Berlin, S. D., \& Miller, P. C. (1992). Practitioners' personal and professional attitudes and behaviors toward religion and spirituality: Issues for education and practice. Journal of Social Work Education, 28(2), 190-203.

Sheridan, M. J., \& Hemert, K. A.-V. (1999). The role of religion and spirituality in social work education and practice: A survey of student views and experiences. Journal of Social Work Education, 35(1), 125-142.

Sheridan, M. J., Wilmer, C. M., \& Atcheson, L. (1994). Inclusion of content on religion and spirituality in the social work curriculum: A study of faculty views. Journal of Social Work Education, 30(3), 363-376.

Sherwood, D. A. (2002). Ethical integration of faith and social work practice: Evangelism. Social Work \& Christianity, 29(1), 1-12.

Shor, I. (1996). When students have power: Negotiating authority in a critical pedagogy. Chicago: University of Chicago Press.

Sparks, D. (2003). Honor the human heart. Journal of Staff Development, 24(3), 4953.

Spencer, S. W. (1957). Religious and spiritual values in social casework practice. Social Casework, 38, 519-526.

Tabachnick, B. G., \& Fidell, L. S. (2001). Using Multivariate Statistics (Fourth ed.). Boston: Allyn and Bacon.

Thompson, E. H., Jr. (1991). Beneath the status characteristic: Gender variations in religiousness. Journal for the Scientific Study of Religion, 30(4), 381-394.

Van Soest, D. (1996). The influence of competing ideologies about homosexuality on nondiscrimination policy: Implications for social work education. Journal of Social Work Education, 32(1), 53-65.

Webster's Seventh New Collegiate Dictionary. (1967). Springfield, Massachrsetts, USA: G. \& C. Merriam Company. 
Woodhead, L. (2001). Feminism and the sociology of religion: From gender-blindness to gendered difference. In R. K. Fenn (Ed.), The Blackwell Companion to Sociology of Religion (pp. 67-84). Malden, Massachusetts: Blackwell Publishers.

Wringe, C. (2002). Is there spirituality? Can it be part of education? Journal of Philosophy of Education, 36(2), 157-170.

Wulff, D. M. (1996). The Psychology of religion: An overview. In E. P. Shafranske (Ed.), Religion and the clinical practice of psychology (pp. 43-70). Washington, DC: American Psychological Association. 


\section{Appendices}

APPENDIX A: Transcripts of participant contacts

1. Phone message

2. Initial Email

3. Follow up email to those who have not responded

4. Starbucks Card

APPENDIX B: Website Cover letter

APPENDIX C: Faculty Survey

APPENDIX D: Human Subjects Application

APPENDIX E: Correlation Table for Research Questions 4-7 


\section{Appendix A \\ Transcripts of Participant Contacts}

\section{Telephone message}

Hello professor

My name is Leslie Wuest. I am a doctoral student at Portland State University in Portland, Oregon. I would like to ask for your help, and invite you to participate in my doctoral research survey. I am surveying faculty members who teach at the top 20 schools of social work in the country, and have selected your name from a list of faculty members in your program. In a couple of days, you will receive an email from me which will tell you more about the short survey, which takes about 10 to 15 minutes to complete. If you agree to participate, there will be a link in the email which will take you to the survey, which you can complete and submit online. The subject line of the email will say "Short Faculty Survey from Leslie Wuest." I want to thank you ahead of time for your consideration and your time.

\section{Initial Email}

Dear Professor (name),

My name is Leslie Wuest, and I am a doctoral student at Portland State University, School of Social Work. I would like to invite you to participate in a study of social work faculty members' experience with the topic of spirituality in classroom discussions.

You are being asked to take part because you have been selected as a faculty member in one of the top twenty schools of social work according to US News and World Reports. As part of the study, I am interested in whether the topic of spirituality comes up in class, and if so, if the resulting discussion is in your opinion a constructive learning experience. I would like to have the widest possible range of responses, so please consider participating in this survey even if you do not have much experience with the subject. The information I collect will help us to better understand the degree to which spirituality is discussed in social work classrooms, and factors associated with constructive discussions of spirituality in social work classrooms.

If you decide to participate, you will be asked to complete an online quantitative survey, which involves answering questions about your classroom experience with spirituality in social work education, as well as your personal experiences regarding spirituality. It should take approximately 10 to 15 minutes to complete. 
Sincerely,

Leslie Wuest

Portland State University

3. Follow up email to those who have not responded

Dear Professor (name),

My name is Leslie Wuest, and I am a doctoral student at Portland State University, School of Social Work. I would again like to invite you to participate in a study of social work faculty members' experience with the topic of spirituality in classroom discussions.

In order to get accurate data, I need to hear from those who do not have experiences with spirituality as well as those who do about whether the topic of spirituality comes up in your classes. Your experience as a faculty member in one of the top twenty schools of social work is valuable to me, and I would like you to consider participating in this survey.

If you decide to participate, you will be asked to complete an online quantitative survey which involves answering questions about your classroom experience with spirituality in social work education, as well as your personal experiences regarding spirituality. It takes only 10 to 15 minutes to complete.

Sincerely,

Leslie Wuest

Portland State University

\section{Starbucks Card}

Amount: $\$ 5$

To: (faculty member's name)

From: Leslie Wuest, Portland State University

You recently received an email invitation to participate in my doctoral research web survey.

If you have already completed my faculty survey,

THANK YOU very much!!

If not, please accept this complimentary Starbucks Card.

Enjoy a coffee break on me. 


\section{Appendix B \\ Website Cover Letter \\ Faculty Survey}

You are invited to participate in a research study conducted by Leslie Wuest, as part of her doctoral program at Portland State University's School of Social Work, under the supervision of Dr. Daniel Coleman. The study investigates social work faculty members' experience with the topic of spirituality in classroom discussions.

You have been selected as a faculty member in one of the top twenty schools of social work according to US News and World Reports. The survey asks whether the topic of spirituality comes up in class, and if so, if the resulting discussion is in your opinion a constructive learning experience. The information collected will help us to better understand factors associated with constructive discussions of spirituality in social work classrooms. If you decide to participate, you will be asked to complete an online quantitative survey, which includes questions about your classroom and personal experiences regarding spirituality. The survey should take approximately 10 to 15 minutes to complete.

As a result of participation in this study, you may experience some discomfort depending on the nature of your experience with the topic of spirituality, but no more than you might typically encounter in the course of daily life. You may not receive any direct benefit from taking part in this study, but your participation may contribute to knowledge that helps those involved in educational training and curriculum development.

Any information that is obtained in connection with this study and that can be linked to you or identify you will be kept confidential. Participant emails will be used ONLY to notify the researcher that you have agreed to be a part of this study. It will NOT be possible to link this email address with your specific responses, and will NOT be used for any other purpose.

Participation is entirely voluntary. Your decision to participate or not will not affect your relationship with the researcher or with Portland State University in any way. If you decide to take the survey, you may choose to stop at any time. Please keep a copy of this page for your records.

If you have concerns or problems about your participation in this study or your rights as a research subject, please contact the Human Subjects Research Review Committee, Office of Research and Sponsored Projects, P.O. Box 751, Portland, Oregon, 97207 or call 1-(877) 480-4400. If you have questions about the study itself, contact Leslie Wuest atwuestl@pdx.edu. 
Appendix C

Faculty Survey

\section{A. The following questions ask for general information about your teaching position:}

1 How many years have you taught at a university level?

years

2. In what social work program(s) do you teach? Please check all that apply.

Undergraduate program

Master's program

Doctoral program

3. Do you teach: ___ Full Time __ Part Time

4. Is your position: __ Tenure Track __ Tenured __ Non-tenure track N/A

5. Degree held:

MSW

$\mathrm{PhD}$

Other degree

B. The following questions ask about strategies used to promote respectful discussion about sensitive issues in your classroom.

Please indicate how frequently you use each of the following strategies.

6. Classroom rules for respectful discussion are explained verbally or in writing.

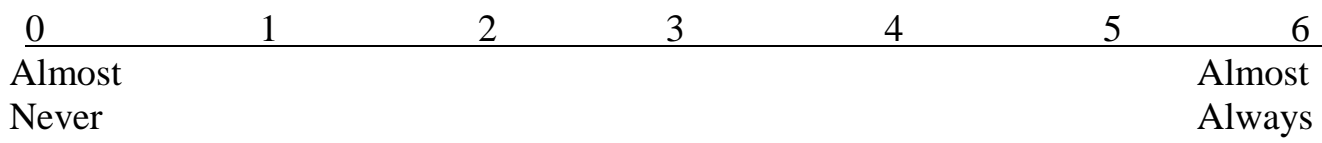

7. Modeling acceptance of diversity in lectures and responses to students.

\begin{tabular}{llllrr}
0 & 1 & 2 & 3 & 4 & 5 \\
\hline Almost & & & & Almost \\
Never & & & & Always
\end{tabular}

8. Active facilitation of classroom dynamics to ensure respectful discussion.

\begin{tabular}{lllrrr}
0 & 1 & 2 & 3 & 4 & 5 \\
\hline Almost & & & & Almost \\
Never & & & & Always
\end{tabular}

9. Other Strategies 
C. The following questions ask about your experiences in the classroom with spirituality as an aspect of diversity.

For the purposes of this study, spirituality is defined as the human search for meaning, purpose and connection with self, others, the universe, and ultimate reality, however one understands it. This may or may not be expressed through religious forms or institutions.

10. Is content on spirituality included in the syllabus, readings or lectures of any courses you teach?

YES NO

If no, please skip to question number 17.

If yes, please identify three particular courses you teach, and indicate the extent to which spirituality is a topic of discussion during a typical term or semester.

11. Course title:

\begin{tabular}{cllll}
\hline 0 & 1 & 2 & 3 & 4 \\
none & mentioned & $\begin{array}{l}\text { brief } \\
\text { discussion }\end{array}$ & $\begin{array}{l}\text { moderate } \\
\text { discussion }\end{array}$ & $\begin{array}{l}\text { substantial } \\
\text { discussion }\end{array}$
\end{tabular}

12. Course title:

\begin{tabular}{clllc}
\hline 0 & 1 & 2 & 3 & 4 \\
none & mentioned & brief & moderate & substantial \\
& & discussion & discussion & discussion
\end{tabular}

13. Course title:

\begin{tabular}{cllll}
\hline 0 & 1 & 2 & 3 & 4 \\
none & mentioned & brief & moderate & substantial \\
& & discussion & discussion & discussion
\end{tabular}


The next questions ask how the topic of spirituality is introduced into course discussion. On average, to what extent are issues of spirituality included in the courses identified above through:

14. Faculty initiated discussion:

\begin{tabular}{lrrrrr}
0 & 1 & 2 & 3 & 4 & 5 \\
\hline Almost & & & & \\
Never & & & & Almost \\
& & & & Always
\end{tabular}

15. Coverage in textbooks:

\begin{tabular}{lrrrrrr}
0 & 1 & 2 & 3 & 4 & 5 & 6 \\
\hline Almost & & & & & & Almost \\
Never & & & & & Always
\end{tabular}

16. Assigned readings (other than textbooks):

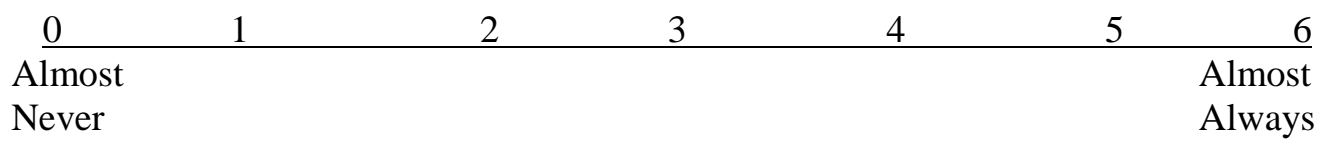

Other

On average, to what extent do students bring up issues of spirituality through:

17. Student initiated discussion during class:

\begin{tabular}{lrrrrr}
0 & 1 & 2 & 3 & 4 & 5 \\
\hline Almost & & & & & Almost \\
Never & & & & Always
\end{tabular}

18. Individual consultation with you, the professor:

\begin{tabular}{lrrrrr}
0 & 1 & 2 & 3 & 4 & 5 \\
\hline Almost & & & & & Almost \\
Never & & & & Always
\end{tabular}

19. Content in student essays or written assignments:

\begin{tabular}{lrrrrr}
0 & 1 & 2 & 3 & 4 & 5 \\
\hline Almost & & & & Almost \\
Never & & & Always \\
Other & & & \\
\hline
\end{tabular}




\section{In your experience:}

20. Do classroom discussions which include spirituality lead to constructive learning experiences?

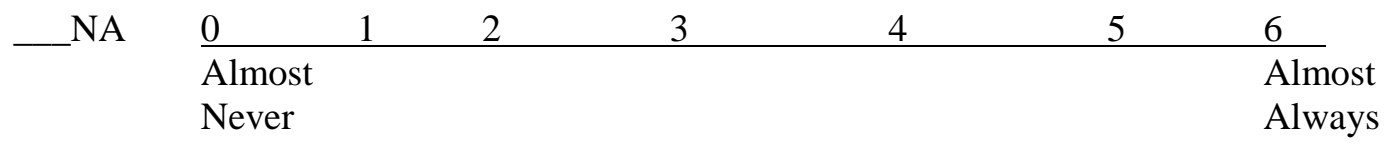

21. Do classroom discussions of spirituality lead to conflict or heated discussion?

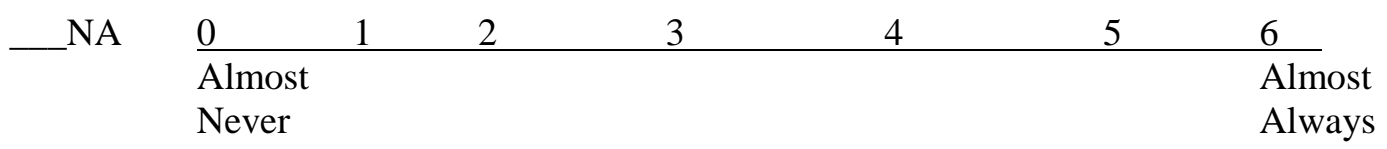

22. When spirituality becomes the topic of discussion in your classes, how prepared are you to discuss this topic?

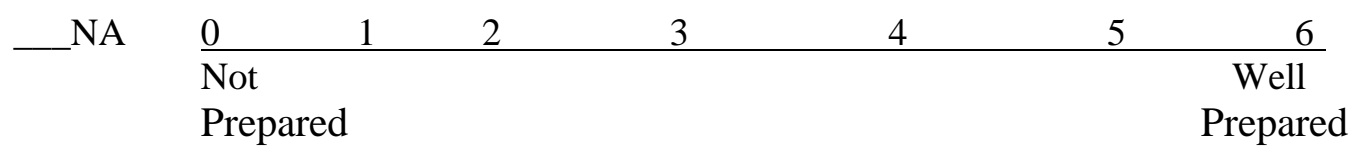

Comments?

23. Are you aware of textbooks that address spirituality in relation to social work practice?

$$
\text { YES NO }
$$

24. To your knowledge, do other faculty members incorporate spirituality into their classes?

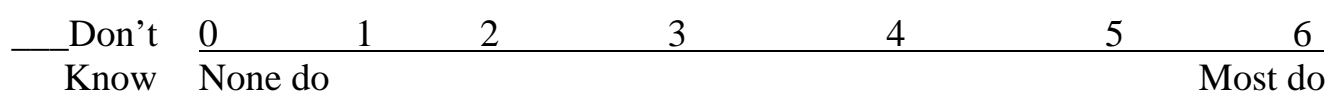

25. In your own social work graduate education and training, content on spirituality and religion was presented:

\begin{tabular}{lrrrrrr}
0 & 1 & 2 & 3 & 4 & 5 & 6 \\
\hline Almost & & & & & & Almost \\
Never & & & & Always
\end{tabular}


26. Rate your satisfaction with the amount of content on spirituality and religion included in your own graduate education.

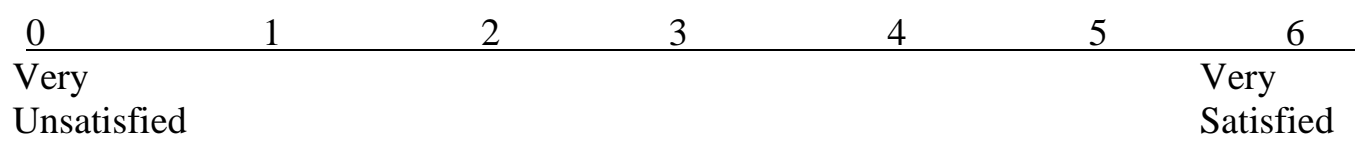

Comments?

27. Assume that there is a proposal for offering a course on social work and spirituality and/or religion within your program at your school and you have been asked to vote on whether to offer such a course. How would you vote?

Against
For, only as an elective
$\ldots \quad$ For, as a requirement in the clinical track only
$\quad \quad$ For, as a required course

28. Does your school currently offer a separate course on social work and spirituality and/or religion?

- YES — NO

\section{Please indicate your level of agreement with the following:}

29. Spirituality is a fundamental aspect of being human.

\begin{tabular}{lllllll}
0 & 1 & 2 & 3 & 4 & 5 & 6 \\
\hline Strongly & & & & & & Strongly \\
Disagree & & & & & Agree
\end{tabular}

30. Knowledge of clients' religious or spiritual belief systems is important for effective social work practice.

\begin{tabular}{lllllll}
0 & 1 & 2 & 3 & 4 & 5 & 6 \\
\hline Strongly & & & & & & Strongly \\
Disagree & & & & & Agree
\end{tabular}




\section{The final section includes questions on your ideological perspective and background variables.}

31. What is your age? (years)

32. What is your gender?

1. Male

2. Female

33. What is your race/ethnic group?

1. African-American/Black

2. Latino/Hispanic-American

3. Asian-American/Pacific Islander

4. Native-American/Alaskan Native

5. Euro-American/White

6. Bi-racial/Multi-racial

7. Other (specify:

34. What is your current religious affiliation or spiritual orientation?

1. Agnostic

2. Atheist

3. Buddhist

4. Christian Catholic

_ Mainline Protestant

_ Evangelical Protestant Other Christian
5. Existentialist

6. Jewish

Orthodox Conservative Reformed

7. Muslim Other Jewish

8. Spiritist

9. Other (please specify:

10. None

35. How frequently do you currently attend religious services?

not at all

less than once a year

once a year

several times a year

once a month
2-3 times a month nearly every week every week more than once a week 
36. During your elementary school years, how often did you attend religious services?

_ not at all

_ less than once a year

once a year

several times a year

once a month
_ 2-3 times a month

_ nearly every week

every week

more than once a week

37. How would you describe your reaction to religious experiences in your past:

$\begin{array}{llccccc} & 1 & 2 & 3 & 4 & 5 & 6 \\ \text { very } & & & \text { neutral } & & & \text { very } \\ \text { negative } & & & & & \text { positive }\end{array}$

38. How frequently do you currently participate in personal spiritual or religious practices (e.g., meditation, reading scripture or spiritual texts, prayer, sacred music, spiritual journaling, or other spiritual exercises)?

never

only on certain occasions

once a month

several times a month

nearly every week once a week several times a week daily several times a day

39. How many of your friends, family members or acquaintances value spirituality or religion?

\begin{tabular}{ccccccr}
0 & 1 & 2 & 3 & 4 & 5 & 6 \\
\hline None & One & Two & Three & Four & Five & More
\end{tabular}
than 5

(If "none," move to question 40.) 
In general, how would you describe your relationships with friends and/or family members who value spirituality or religion?

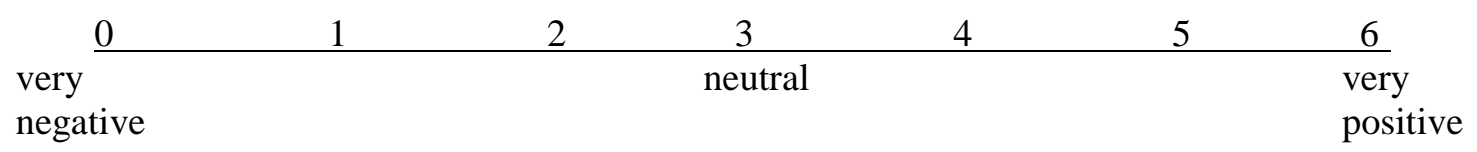

40. Please indicate your present relationship to an organized spiritual or religious group.

_ Active participation, high level of involvement

Regular participation, some involvement

Identification with spiritual or religious group, very limited or no involvement

_ No identification, participation, or involvement with spiritual or religious group

_ Negative reaction to spiritual or religious tradition

Please add any comments you would like to make:

Thank you so much for participating in this survey! 


\title{
Appendix D
}

\author{
Human Subjects Application
}

\section{Project Title and Prospectus:}

Title: Factors associated with inclusion of spirituality in secular social work education

\section{Prospectus:}

The purpose of this research study is to examine the extent to which spirituality is currently included by faculty in social work courses, factors which predict inclusion of spirituality as a topic in classroom discussion, and factors predicting constructive classroom discussion about spirituality. Social work practice involves interaction with the wide variety of different racial and cultural groups currently represented in American society. In order to work within this multicultural environment, social workers must be able to respect and value people with a wide range of personal characteristics, values, and lifestyles, including different value systems and ideological perspectives. In order to form productive relationships and interact in meaningful ways with clients, social workers must be able to understand the client's perspective, which may be informed by spiritual understandings of the world and their place in it. Accordingly, the Council on Social Work Education's Educational Policy and Accreditation Standards (Council on Social Work Education, 2001) acknowledges that religion, an aspect of diversity, and spirituality, an aspect of human development, are among client characteristics social work education needs to address in order to "[prepare] social workers to practice without discrimination, with respect, and with knowledge and skills."

Although there is general consensus among social work practitioners and educators that spirituality is relevant to social work education, there is also consensus that social work education in the recent past has not adequately equipped social work students to understand or address issues of spirituality (Ai, 2002; Ai, Moultine, Picciano, Nagda, \& Thurman, 2004; Cnaan, 1999; Dudley \& Helfgott, 1990; Sheridan, Bullis, Adcock, Berlin, \& Miller, 1992; Sheridan, Wilmer, \& Atcheson, 1994). Schools of social work have recently begun to address this problem by incorporating elective courses in spirituality and religion into the curriculum. There has also been an increase in overall research on spirituality in social work, and a corresponding increase in the number of articles in social work journals that address spirituality. Thus far researchers have not specifically investigated the extent to which spirituality is presently included in general coursework in the social work curriculum.

This study will consist of a web-based survey completed by social work faculty who teach courses including discussion of human diversity. Two previous studies have been conducted exploring social work faculty views of religion and spirituality, one on the East Coast (Dudley \& Helfgott, 1990), and one in the Southeast (Sheridan et al., 1994). The proposed research will replicate several items on these surveys, and advance our understanding further by exploring faculty behaviors in the 
classroom related to inclusion of spirituality as a topic. Data collected will assist researchers in learning the extent to which faculty incorporate the topic of spirituality in courses, and individual, classroom, and school level factors which predict inclusion of spirituality.

\section{Exemption Claim for Waiver of Review}

None.

\section{Subject Recruitment}

Participants will be faculty members in fully accredited schools of social work located in secular universities identified as among US News and World Report's twenty top-ranked Social Work programs in the United States. I expect to identify 300-400 potential participants on school web sites, locating course schedules with listings for individual courses with content related to diversity, human behavior in the social environment, and direct social work practice. Roughly the third week of the school's Fall semester or term, identified faculty members will receive a telephone message in their school voicemail inviting them to participate in a short doctoral student survey, asking them to watch for an email regarding the study in a few days (Appendix A). A few days later the faculty member will receive the first email with more information about the survey. If they are interested in participating, they may click the link to the survey webpage, where they will find more information. The same day the first email is sent, a card will be mailed to the faculty members' school address with a $\$ 5$ gift card to Starbucks to thank those who have already completed the survey, and a complimentary gift for those who have not yet taken the survey.

Faculty who do not respond to the initial email will be re-contacted by email two additional times at one-week intervals following the initial email, unless they indicate their wishes by clicking the button stating "I decline to participate." Results of the survey will be collected and stored on the WebSurveyor server maintained by Portland State University Office of Information Technology.

\section{Informed Consent}

A waiver for signed informed consent is requested. The initial screen on the website containing the survey consists of a cover letter with detailed information about study participation (Appendix C). After the faculty member reads the cover letter, they must click on a button that will read, "I agree to participate," in order to gain access to the survey.

\section{First-Person Scenario}

"I received a message on my office phone last week regarding a doctoral student survey of social work faculty members, telling me that I would receive an email in a few days containing more information about the survey, and that the survey would take 10-15 minutes to complete. I later received the email, which explained that the survey examined faculty members' experience with the topic of spirituality in classroom discussions. This e-mail provided me with a link that directed me to a website. The website contained a cover letter that provided further information about 
my participation in the study. Once I decided to participate, I clicked on a button reading, 'I agree to participate,' and gained access to the survey. I completed a brief survey that took approximately 10-15 minutes. When I was done with the survey, I clicked on another button reading, 'Submit survey."'

\section{Potential Risks and Safeguards}

It is highly unlikely that any psychological risks will be posed for participants answering the survey questions. The survey questions may potentially remind participants of negative experiences with spirituality in the past, although not unlike exposure to spirituality normally encountered in the course of daily life. Participants may elect to stop answering questions at any time. Everyone who is eligible to take this survey is a professional social worker and has been trained in dealing with personal issues in the context of their professional work.

\section{Potential Benefits}

Participants may not receive any direct benefit from taking part in this study, but the study may help to increase knowledge that may help those involved in educational training and curriculum development. All faculty members invited to participate will receive a complimentary $\$ 5$ Starbucks Card.

\section{Records \& Distribution}

Survey data and email addresses of participating faculty will be assigned a non-identifying ID number and stored on a separate drive on a password protected server maintained by Portland State University's Office of Information technology. The database is highly restricted and accessible only by the proper account and password. When the data have been collected, they will be exported through another restricted account using a Microsoft Access ODBC link. From here the table will be exported, printed and read into SPSS for analysis and stored in an SPSS data file. The SPSS file will reside on the researcher's removable drive and a back up disk, both of which will be stored in a locked filing cabinet. Printed versions of the data will be stored in a locked filing cabinet and retained for a minimum of three years following completion of the research.

\section{References}

Ai, A. L. (2002). Integrating spirituality into professional education: A challenging but feasible task. Journal of Teaching in Social Work, 22(1/2), 103-128.

Ai, A. L., Moultine, K., Picciano, J. F., Nagda, B., \& Thurman, L. H. (2004). Integrating spirituality into the social work curriculum: A student-initiated program evaluation. Journal of Teaching in Social Work, 24(1/2), 105-127.

Cnaan, R. A. (1999). The Newer Deal: Social work and religion in partnership. New York: Columbia University Press. 
Council on Social Work Education. (2001). Educational Policy and Accreditation Standards .

Dudley, J. R., \& Helfgott, C. (1990). Exploring a place for spirituality in the social work curriculum. Journal of Social Work Education, 26(3).

Sheridan, M. J., Bullis, R. K., Adcock, C. R., Berlin, S. D., \& Miller, P. C. (1992). Practitioners' personal and professional attitudes and behaviors toward religion and spirituality: Issues for education and practice. Journal of Social Work Education, 28 (2), 190-203.

Sheridan, M. J., Wilmer, C. M., \& Atcheson, L. (1994). Inclusion of content on religion and spirituality in the social work curriculum: A study of faculty views.

Journal of Social Work Education, 30(3), 363-376. 


\section{Appendix E}

Correlation Table for Research Questions 4-6

\begin{tabular}{|c|c|c|c|c|c|c|c|c|c|}
\hline & 1 & 2 & 3 & 4 & 5 & 6 & 7 & 8 & 9 \\
\hline 1. Faculty inclusion scale & - & & & & & & & & \\
\hline 2. Personal experience scale & $.17 *$ & $\underline{-}$ & & & & & & & \\
\hline 3. Student inclusion scale & $.55^{* *}$ & $.20 * *$ & 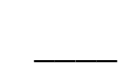 & & & & & & \\
\hline 4. Use of rules & $.17 *$ & -.01 & $.23 * *$ & 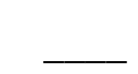 & & & & & \\
\hline 5. Modeling and facilitation & $.16^{*}$ & -.12 & .08 & $.38 * *$ & $\underline{-}$ & & & & \\
\hline 6. Constructive discussions & $.38 * *$ & .12 & $.38 * *$ & $.23 * *$ & $.29 * *$ & 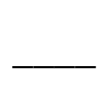 & & & \\
\hline 7 .Age & .01 & .04 & -.04 & $-.15^{*}$ & -.07 & .07 & $\underline{-}$ & & \\
\hline 8. Female gender & $.21 * *$ & -.09 & $.14^{*}$ & .04 & $.14^{*}$ & .06 & -.09 & _ & \\
\hline 9. Full time & $.14^{*}$ & .08 & .07 & .02 & .05 & .06 & .11 & .03 & 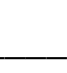 \\
\hline 10. Ethnic minority & -.10 & .12 & -.11 & -.00 & -.07 & -.04 & $-.18 * *$ & -.08 & .01 \\
\hline
\end{tabular}

